\title{
Alternative splicing of the sex determination gene transformer-2 is sex-specific in the germ line but not in the soma
}

\author{
William Mattox, ${ }^{1}$ Melanie J. Palmer, and Bruce S. Baker \\ Department of Biological Sciences, Stanford University, Stanford, California 94305 USA
}

\begin{abstract}
The transformer-2 (tra-2) gene of Drosophila melanogaster plays essential roles in both sexual differentiation in the female soma and spermatogenesis in the male germ line. In the female soma, tra-2 is known to act with other genes in the sex determination regulatory cascade to control the sex-specific alternative splicing of transcripts from the doublesex gene. Here, we determine whether or not any sex-specific tra-2 products are expressed that may account for either of these sex-specific activities. Sequence analysis of the tra-2 gene and 10 tra-2 cDNA clones coupled with nuclease protection analysis reveals a variety of alternatively spliced tra-2 mRNAs that each encode one of four distinct but overlapping polypeptides. Three of the encoded polypeptides contain both a ribonucleoprotein consensus sequence and arginine/serine-rich regions, suggesting a direct role for these products in RNA splicing. We show that although two transcripts are expressed male specifically in the germ line, the tra-2 transcripts expressed in the soma are not sex-specific. The translation of products from a tra-2-lac $Z$ fusion gene in both sexes suggests that the female-specific functioning of tra-2 in somatic tissues is not attributable to a translational mechanism. We suggest that tra-2 activity in somatic tissues is regulated through a post-translational sex-specific interaction with the product of the tra gene rather than through the expression of a female-specific tra-2 polypeptide.
\end{abstract}

[Key Words: Drosophila; sex determination; RNA splicing; transformer-2; ribonucleoprotein consensus sequence; germ line]

Received January 5, 1990; revised version accepted February 8, 1990.

The regulation of alternative RNA splicing has emerged as an important mechanism for the developmental control of gene expression. For many genes, alternative splicing pathways are employed for the tissue-specific or stage-specific expression of mRNAs that encode different protein isoforms (for review, see Breitbart et al. 1987). In other cases, alternative splicing serves to regulate gene expression on and off by determining whether or not an RNA encoding an open reading frame (ORF) for the functional polypeptide is expressed (for review, see Bingham et al. 1988). Despite the fact that alternative splicing is known to play an important role in the regulated expression of a number of gene products, little is currently known about the mechanisms that govern the usage of alternative splicing pathways. The hierarchy of regulatory genes controlling somatic sexual differentiation in Drosophila melanogaster (for reviews, see Baker and Ridge 1980; Baker and Belote 1983; Cline 1985) provides an excellent opportunity to study regulatory interactions that govern alternative splice choices. In this hierarchy, a cascade of alternative splicing events form the

${ }^{1}$ Corresponding author. molecular basis for a series of genetic regulatory interactions that ultimately control the somatic sex of the fly (for reviews, see Baker et al. 1987; Baker 1989). This makes it possible to study both the genes that regulate alternative splicing and those that encode the premRNA molecules, which are the subject of this regulation.

The primary determinant of sex in Drosophila is the ratio of X chromosomes to sets of autosomes (the X/A ratio; Bridges 1921). The genes in the sex determination regulatory hierarchy are differentially activated in response to this ratio. Early in the development of chromosomally female individuals (X/A ratio of $2: 2$ ) the Sex-lethal $\{$ Sxl $)$ gene is activated in a process that involves both maternally and zygotically contributed components (Cline 1978, 1980, 1983, 1984, 1985, 1986, 1988; Maine et al. 1985; Oliver et al. 1988; Steinman-Zwicky 1988; Salz et al. 1989). In chromosomally male individuals (X/A ratio of $1: 2$ ), the $S \times l$ gene is not activated. At the molecular level, Sxl pre-mRNA is alternatively spliced in different patterns in chromosomal males and females (Bell et al. 1988). Only in chromosomally female individuals is an Sxl mRNA produced containing the 
long ORF encoding the presumptive $S x 1$ protein. In chromosomally male individuals, pre-mRNA splicing along an alternative pathway generates an RNA in which the Sxl protein-coding region is interrupted by stop codons. The presence or absence of a functional Sxl product, in turn, determines the splicing pattern of the pre-mRNA from the transformer (tra) gene, which is the next known gene in the sex determination hierarchy $(\mathrm{Na}-$ goshi et al. 1988). In chromosomally female individuals, Sxl directs some of the tra pre-mRNA to be spliced into an mRNA that contains an uninterrupted ORF encoding the functional tra protein. Functional Sxl product is absent in males, and as a result, tra pre-mRNA can only be spliced in a pattern that forms an RNA with a truncated ORF in these individuals (Boggs et al. 1987). Both the female-specific tra product and the functional product of the transformer-2 (tra-2) gene are required for the female-specific splicing of pre-mRNA from the doublesex $(d s x)$ gene (Nagoshi et al. 1988). The $d s x$ pre-mRNA is spliced along different pathways in males and females to make mRNAs encoding alternative sex-specific polypeptides (Baker and Wolfner 1988; Burtis and Baker 1989). The polypeptide encoded by the male-specific $d s x$ mRNA functions to repress female sexual differentiation in chromosomally male individuals, whereas the female-specific $d s x$ product, in combination with the product of the intersex gene, functions to repress male sexual differentiation in chromosomally female individuals (Baker and Ridge 1980; Burtis and Baker 1989).

Recent sequence analysis suggests that the products of two genes in the sex determination splicing cascade, tra-2 and $S \times 1$, may play direct roles in RNA splicing reactions (Amrein et al. 1988; Bell et al. 1988; Goralski et al. 1989|. The conceptual translation products of these genes contain sequences that are similar to the highly conserved ribonucleoprotein consensus sequence (RNPCS) (Dreyfuss et al. 1988) that is found in several proteins that bind to RNA (Theissen et al. 1986; Sachs et al. 1986; Swanson et al. 1987; Merrill et al. 1988; Query et al. 1989; Merrill and Williams 1990). The presence of the RNP-CS in the tra-2 and Sxl polypeptides suggests the possibility that these two products bind, respectively, to $d s x$ and tra pre-mRNA molecules to influence their splicing patterns. It is interesting to note that regions required in cis for normal sex-specific splicing have recently been identified within both the $d s x$ and tra premRNAs (Nagoshi and Baker 1989; Sosnowski et al. 1989). It has been suggested that tra-2 and Sxl proteins may regulate RNA splicing through binding in these regions (Burtis and Baker 1989; Goralski et al. 1989; Sosnowski et al. 1989).

Here, we are interested in understanding how the activity of the tra-2 gene is regulated in a sex-specific way. Although the normal functioning of the tra-2 gene is required for correct splicing of $d s x$ pre-mRNA in female somatic tissues (and consequently for their correct female sexual differentiation), it plays no role in $d s x$ splicing in males (Nagoshi et al. 1988). One possible explanation for the female-limited functioning of the tra-2 gene is that somatic tra-2 product(s) are expressed only in females. Two previous studies established that the tra-2 gene is transcribed in both the male and female soma (and the germ line as well), indicating that tra-2 expression is not sex-limited at the transcriptional level (Amrein et al. 1988; Goralski et al. 1989). However, these studies did not exclude the possibility that the synthesis of tra-2 product(s) is regulated in a sex-specific way through any of several possible post-transcriptional mechanisms. The experiments reported here are particularly concerned with distinguishing whether the function of the tra-2 gene is regulated through the use of sexspecific alternative RNA processing pathways, as are the products of the $S \times 1, t r a-2$, and $d s x$ genes, or whether regulation of tra-2 functioning occurs at the translational or post-translational levels.

Whatever the nature of the molecular mechanism is, it seems likely that the regulation of tra-2 function in somatic tissues is accomplished through sex-specific interactions with one or more of the genes in the sex determination regulatory hierarchy. Most attention has been focused on the tra gene as the most likely to directly regulate tra-2 function because tra is known from molecular and genetic studies to function just upstream to or parallel to tra-2 (Baker and Ridge 1980, McKeown et al. 1988; Nagoshi et al. 1988). Another goal of the studies reported here is to clarify the regulatory relationship between tra-2 and the other genes in the regulatory hierarchy including tra.

In addition to its female-specific function in somatic sexual differentiation, the tra-2 gene also plays a separate sex-specific role in the development of male germ line tissue (Watanabe 1975; Belote and Baker 1983). A functional tra-2 product is required for normal spermatogenesis but is not needed for normal development of female germ cells. The precise nature of this male germ line function is unknown but it is unlikely to involve control of $d s x$ RNA splicing because a functional $d s x$ gene is not required in the germ line for male fertility (Schupbach 1982). The fact that the tra-2 gene plays distinct roles in the male germ line and in female somatic cells suggests that tra-2 function is regulated in a tissue-specific way. Another issue that we wish to address here is whether or not the tissue-specific functioning of the tra-2 gene is accomplished through the expression of distinct tissue-specific tra-2 products in the male germ line and the female soma.

To examine the ways in which both sex-specific and tissue-specific aspects of tra-2 activity are controlled, we conducted an extensive analysis of the structure and expression patterns of tra-2 transcripts. Our results show that the tra-2 gene encodes multiple mRNAs that arise through the use of both alternative transcription start sites and alternative RNA splicing pathways. Analysis of the distributions of the various mRNAs suggests that there is a testes-specific tra-2 product that could account for male germ line-specific functioning of the tra-2 gene. However, in somatic tissues no female-specific product was found that could account for the female-specific sex determination function of the tra-2 gene. The latter result has important implications for how the activity of 
the tra-2 gene is regulated by other genes in the sex determination regulatory hierarchy.

\section{Results}

Transcripts from the tra-2 gene are alternatively spliced to produce $m R N A$ s encoding several different polypeptides

Previous RNA blot hybridization studies of transcripts from the tra-2 gene detected a broad band of hybridization at an apparent size of $1.7 \mathrm{~kb}$ in both male and female poly(A) ${ }^{+}$RNAs (Goralski et al. 1989). To determine whether multiple tra-2 mRNAs with similar overall sizes exist, 26 igt10 phage clones containing cDNA inserts homologous to the tra-2 gene were isolated from a third instar larval imaginal disc cDNA library. Comparisons of the restriction maps of these cDNA clones and others (T. Goralski, unpubl.) suggested that there exist several alternatively spliced tra-2 mRNAs (data not shown).

To determine the splicing patterns utilized by tra-2 mRNAs, we sequenced the inserts in 10 tra-2 cDNA clones, each of independent origin, as well as $3.9 \mathrm{~kb}$ of Drosophila genomic DNA that contains the entire tra-2 gene and a substantial amount of flanking sequence. The genomic DNA sequence is shown in Figure 1. Comparison of this sequence with that of the 10 tra-2 cDNA clones indicates that all of the cDNA inserts correspond entirely to genomic sequences between positions +668 and +2972 . Among the cDNA clones, four types of splicing patterns that affect the protein-coding region can be distinguished. These are designated types A, B, C, and $D$. Sequence analysis of three adult cDNA clones (T.J. Goralski and B.S. Baker, unpubl.) revealed no additional types. The structures of the most complete representatives of each cDNA type are depicted in Figure 2.

RNA molecules with the type A structure have 6 exons and encode an ORF of 264 amino acids, beginning with an AUG located within exon 2. Examination of the DNA sequences from three previously reported tra-2 cDNA clones (Amrein et al. 1988; Goralski et al. 1989) revealed that they are each incomplete versions of the type A structure. It should be noted that one of the cDNA sequences originally reported by Amrein et al. (1988) contains a cloning artifact wherein 23 nucleotides from within exon 6 are duplicated at the $5^{\prime}$ end of the cDNA insert in the sense orientation.

The type $B$ mRNA splicing pattern differs by the inclusion of a 188-nucleotide exon (exon 3) not present in type A mRNA. This exon contains multiple stop codons in-frame with the AUG that is located in exon 2 such that translation initiated at this site would produce a polypeptide of only 41 amino acids. However, the splicing of exon 3 to exon 4 in the type B mRNA creates an AUG that is not present in type A mRNA /exon 3 ends with the nucleotides $A U$ and exon 4 begins with G). Because it is known that translation may initiate at AUGs following the first AUG, provided that the upstream ORF terminates before the secondary AUG (for review, see Kozak 1986), we expect that this down- stream AUG is used to initiate translation of a $226-$ amino-acid polypeptide. This product is encoded by the same ORF that is found in type A mRNA and would therefore be a shorter version of the type A polypeptide.

The type $\mathrm{C}$ splicing pattern differs from $\mathrm{A}$ and $\mathrm{B}$ in that a 232-nucleotide intron between exons 3 and 4 is not removed (see Fig. 2). This "unspliced" mRNA structure contains stop codons in all three reading frames that block translation from all AUG initiation codons upstream of exon 4. As a consequence, the AUG codon created in type $B$ splicing is not created in type $C$. The first AUG in-frame with the long ORF in type C RNA is located downstream near the $3^{\prime}$ end of exon 4 . Translation initiating at this site would produce a polypeptide of 179 amino acids from the same reading frame that is open in type A and B mRNAs (see Fig. 2). None of the type C cDNAs extended upstream of a position in the middle of exon 3. Below, we present data suggesting that the type $\mathrm{C}$ cDNA structure represents a fully processed mRNA and is not simply a low-abundance precursor of the type A or B mRNAs.

The type D splicing pattern is similar to type A, except that it uses an alternate acceptor in splicing exon 5 to exon 6 (Fig. 2). This alternate acceptor is located 29 nucleotides upstream of the acceptor that is utilized in type A, B, and C mRNAs. This added 29-nucleotide segment includes two in-frame stop codons that terminate the long ORF. The type D mRNA could encode a truncated polypeptide of 136 amino acids initiated at the AUG in exon 2 and terminated a short distance after the upstream acceptor site of exon 6 (see Fig. 1).

In addition to the variations in splicing pattern described above, each of which has a substantive effect on the tra-2 protein-coding region, several variations in RNA structure were found at positions outside of the protein-coding regions. cDNA clones were identified in which each of three closely spaced splice acceptor sites were used in splicing exon 1 to exon 2 (these acceptors are denoted $\mathrm{x}, \mathrm{y}$, and $\mathrm{z}$ and are located between +840 and +854 in Fig. 1). Although sites $y$ and $z$ are similar to the eukaryotic consensus splice acceptor sequence (Breathnach et al. 1978; Oshima and Gotoh 1987), site x substitutes the sequence $5^{\prime}$-UG/exon-3' for the canonical $5^{\prime}-\mathrm{AG} /$ exon-3'. This nonconsensus splice site is used only at relatively low levels compared to splice sites y and $z$, as is demonstrated by the nuclease protection patterns that are shown in lanes 2 and 3 of Figure $3 \mathrm{~A}$.

The analysis of cDNA clone sequences also identified four closely spaced polyadenylation sites used by tra-2 transcripts. These sites are located in a region between nucleotides +2950 and +2967 that begins 16 nucleotides downstream of a consensus polyadenylation signal 5'-AAUAAA-3' (see Fig. 1).

Taken together, the sequences of tra-2 cDNA clones indicate that there is considerable diversity in the structures of mRNA molecules expressed from the tra-2 gene and that this diversity originates primarily from alternative patterns of RNA splicing. It had been reported previously by Amrein et al. (1988) that there is no alterna- 
$\begin{array}{lllllllllllllllllllllllllllllllll}S & G & R & L & H & C & S & A & R & Y & K & H & K & R & S & A & S & S & S & S & A & G & T & T & S & S & G & H & K & D & R & R\end{array}$

1001 GTGTACACACATATGTGAGACGACCCTAAACGATACCTCTTTTGACATGAAGCATCGAGTAGTITTGACTGGCAGTTIGGAAAAAGGTICAACTGTCAT $\longrightarrow \rightarrow \vec{\sigma}$ germ line starts

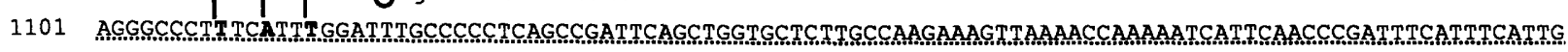

1201 GAAGAAACCAACCAACCAACCAACCAACGAACATCACTAT GTAAGAACCCACCGAAGCAATCATTTTTATTCTACGTCCAACTACCAAAGAATTTGGCCG $\mathbf{M}$

1301 AAAGAGGTCGAACCCAACCGTAGCATTTGTCAAGTCACACAAATTTTCCAACTGTCAGTTACCAAGGCGTGCAAGAACCACCCGAAATCCACACGAAATA

1401 CAAAACTTTTCAAGACCCTCAAGAACGAACCGCAAGATAATCTTATTTCATTCCATTCCACATCGAATCAAGGTCTGACTACGATTACTGTGGCAGTCGC

$15010 \begin{array}{llllllllll} & \text { S } & \text { Y } & Y & C & G & S & R\end{array}$

1501 CGGCACCAGCGGTCCTCCTCTCGCCGACGCTCCCGITCGCGTTCCTCCTCGGAGTCGCCGCCACCGGAGCCGCGTCATCGCTCCGGACGTTCATCACGCG

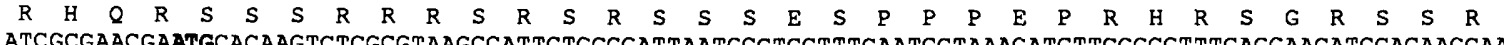
1601 ATCGCGAACGAATGCACAAGTCTCGCGTAAGCCATTCTGCCGATTAATGCCTCCT TTCAATCCTAAAGATCTTCGGCGTTTCAGGAACATCCACAAGCAA

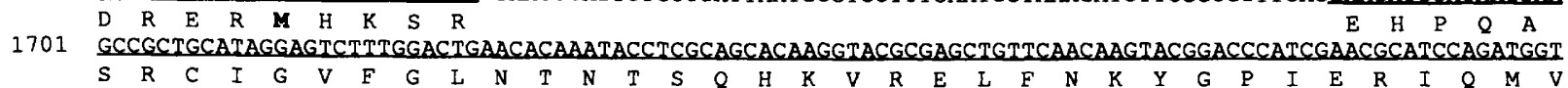
1801 GATTGACGCACAAGTAAGTCGGTTTTCGATAAGCATTGCTAAGATATTTCCTGCCTGAATCCTTTTGTGTAGACAAATCCGCTGAAGCCCTGCAGTTTTG I $D$ A $Q$

1901 TCTTAATTTCTGGCTAGATAAAATTTGATAGCGATTGTGAGTTTTTGTGTATTCCAAACTAAAAGCTAAAGGCTTGCTGTCACAGTGGCATATTGTTCGA

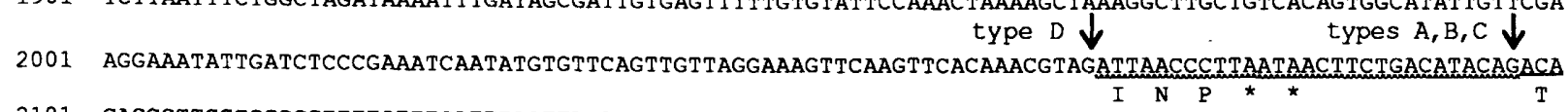
2101 CAGCGTTCCCGGGGCTTITGTTTCATTTACTTTGAGAAACTCAGCGATGCCCGCGCGGCTAAGGACAGCTGCTCCGGAATAGAAGTGGATGGTCGCCGTA $\begin{array}{lllllllllllllllllllllllllllllllllll}2 & Q & R & S & R & G & F & C & F & I & Y & F & E & K & \text { L } & \text { S } & \text { D } & \text { A } & R & A & \text { A } & K & \text { D } & \text { S } & \text { C } & S & G & \text { I } & E & \text { V } & D & G & R & R\end{array}$ 2201 TTRGCGTCGATTTCTCTATAACCCAACGGGCTCATACCCCAACTCCGGGTGTGTATTTGGGTCGTCAGCCGCGTGGAAAAGCTCCACGCTCATTTTCACC 2301 GCGTAGAGGACGCCCGTGTGTATCACGATCGCTCC

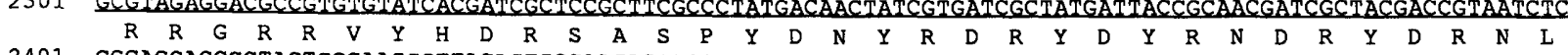
2401 CGCAGGAGCCCTAGTCGCAACCGTTACACTCGCAACAGGAGCTACAGCCGTTCACGCTCTCCGCAACTACGTAAAGTTTATTCCTCCGTCTATTTAATCA $\begin{array}{lllllllllllllllllllllll}R & R & S & P & S & R & N & R & Y & T & R & N & R & S & Y & S & R & S & R & S & P & Q & L\end{array}$

2501 AACGTTTATCCTGTATATTTTCCACGATTAGGTCGAACTTCATCGCGCTATTAAAGCGCCTGGGGAGGAGGCTACTTCATTAACTCGTGCTCCTAAGTTC $R \quad R \quad T$ S S R Y *

2601 GCCCAACTGGATTGTGTCAAACGGGCTGTAAAGGAGCATACGACTGAAATATTGTGTTTTGGTGAATCCTATCCCATCTAATGCATTTGGTTGGCGAACA 2701 GITCGCAACTAGATTAATTAATTATTCACCCAAAACACCCTTTAATCATAATAATTCGGTTACTATTATTAATGCTGTATAAAAACATAAATTGTAAATA 2801 TCAAATCAATTACCAACATTACATACAGAGGTCCGCATGGATTGTGATATGTATTTTAAAGGAACTGCAGCAAACTGATAATGATAACATTAAACTAATI 2901 TTAATTATAAATGCAATTGTGCAGCAGGTACAAMATAAAGATTAATTTGTACAGMAGGACGATT MACTTGTGAATGGGCGTTTTATTGAATTGGTCGTA 3001 CATATCATT TACT TAAGCTTCTATAAATTTCAGTTTAATTAGGATTAACTAAGTTTGTATGGGAAGCAGAACCGGTCATACACTTACTCAATGGATCTCC 3101 ACAGGATACAAATGCATTCTTTGGAAAACGCTCAAGTAGCACTGGGATTTGCACTTGCCGACGCTGAAGTAGAGGCCTCCAGGGATGTACCTGCTCCGCT 3201 CGATGTCTGTGTCGCTCGAGAGGCTTTGTAGGCCAGCTCTAGGGTCTGGTTAATCGTATGCATGTCCCCCTCTATGCTGCGTGCCCAGTTCTCCACGTCG 3301 CCGAGATCCTTTAGGGCAGTGCTGAATTGGTCGATGAGCTGCAGCCATTGGTGGGTCTGCTTGGCGAAATTGGTGGCGCCCAAGTGCAGTTGCTTTGCCT 3401 CTGCGTCCAGCCGCTTCTGGTTCAGGTAGGCCTGAGCCACGCCCACATTTAGGGTGTCCACTCAGAGACTGAGTGAGCTCATTGGACGCTTCTAGTTGCC 3501 TCCTTTCGACGCACCTTGAAATT TAAGCCTTGTAATCGTTTGTGCCAAATACAAACTACAATTGGCCTTGTACCCTGTTCCTGTTTTCGCTTCGCCTGCT 3601 CCTTGTGATGCTCCT TAACCATGGAAGTTAACATATTCAAGCTTATTGCAAACAAATCCAAAGAAAAAACAATTTTTGTCCAAACACT TGAAATCAGCTG 3701 ATTTGCTAAAGACGAGCCAAGACCGATAGATAATTTCGATAAGCAGATTGACCGTTAAAATCGATACGGTTCCACCTCTAATAGCCACACACGTGCGCGG 3801 CTGTTGCGCTCATCTTTTTCTCGAGTTTTTATAGAAATCGTGGCTTAAATAAGGCAAAATGGGGTCTAAACGCGCGATGGACGTGCACATGTTCCCTTCG 3901 GACCTGAATTC 3911

Figure 1. Complete genomic sequence of the tra-2 gene. The sequence of the tra-2 gene and flanking DNA are presented. Coding sequences are translated into single-letter amino acid abbreviations below the DNA sequence. Asterisks $\left({ }^{*}\right)$ denote stop codons. Exon sequences are underlined. Those regions that vary between transcripts due to alternative splicing, multiple initiation, or polyadenylation sites are indicated with a broken underline, with the exception of the intron between exons 3 and 4 (included in type $C$ transcripts), which is indicated by italics. The precise positions of alternative splice acceptors and major transcription initiation sites are indicated by arrows. Major transcription initiation sites, TATAA-like sequences, the three putative initiation codons, the polyadenylation signal, and sites of polyadenylation are all highlighted with boldface type. Both the genomic and the type B cDNA sequences have been submitted to the Genbank data base and have been given accession numbers M30939 and M30940, respectively.

tive splicing of tra-2 transcripts; however, the probes used in the nuclease protection experiments that formed the basis for this conclusion originated from an incomplete cDNA clone and would not have detected any of the types of structures reported here.
100

200

300

500

600

700 800

900

1000

1100

1200

1300

1400

1500

1600

1700

1800

1900

2000

2100

2200

2300

2400

2500

2600

(1)

As summarized above, the alternative tra-2 RNA splicing patterns serve to vary the probable sites at which translation initiation and/or termination of the encoded polypeptides occurs. Through changes in the translation start and stop sites, alternative splicing po- 


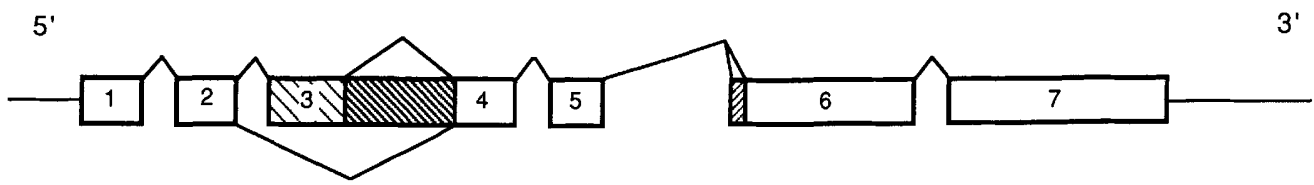

\begin{tabular}{|c|c|c|c|c|c|c|c|}
\hline & & & AUG & & & & \\
\hline Type A & & 1 & 2 & 4 & 5 & 6 & 7 \\
\hline 264 amino acids & & & $2^{2}$ & & & 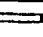 & \\
\hline & & & & & & & \\
\hline Type B & 1 & 2 & (3) & 4 & 5 & 6 & 7 \\
\hline 226 amino acids & & & & & 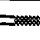 & 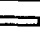 & \\
\hline & & & & & & & \\
\hline Type C & $E$ & & & 4 & $\overline{5}$ & 6 & 7 \\
\hline 179 amino acids & & & & $\mathrm{NH}_{2}$ & & 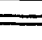 & \\
\hline & & & & & U & & \\
\hline Type D & & 1 & 2 & 4 & 5 & 6 & 7 \\
\hline 136 amino acids & & & & & & & \\
\hline
\end{tabular}

Figure 2. Alternative splicing patterns of tra-2 RNA. Four splicing alternatives for tra-2 RNA, as deduced from comparison of genomic and cDNA sequence data, are shown. The arrangement of exons in the genome is shown in the first line, and the spliced transcript structures represented by the most complete cDNA clones of each type are shown below. Boxes represent exons. Crosshatched regions indicate the alternatively spliced segments. The narrower bar below each cDNA type indicates the extent of the longest polypeptide encoded by that transcript. Only the translation initiation and termination codons that define these longest ORFs are shown. The stippled region within each polypeptide indicates the position of the RNP-CS sequence, and the solid regions indicate the arginine/serine-rich domains. Key: $₫ \mathbb{Q}$ alternatively spliced segments. Arg-Ser rich regions.

tentially allows at least four different polypeptides to be produced from sequences in the tra-2 gene. These four polypeptides form a family of structurally related products in that the sequences of each of them substantially overlap the others.

The existence of multiple tra-2 products suggests that different tra- 2 functions may be carried out by different polypeptides and raises the possibility that tissue-specific or sex-specific tra-2 functions are regulated by alternative RNA splicing. A mechanism wherein tra-2 function is regulated at this level would fit well with previous studies, which found that tra-2 activity must be controlled post-transcriptionally because the tra-2 gene is transcribed in both those tissues where its function is known to be needed (the female soma and male germ line) and those in which it is not needed (the male soma and female germ line) (Amrein et al. 1988; Goralski et al. 1989). In the following sections, we consider different ways in which alternative RNA splicing might serve to regulate tra-2 function and determine whether or not any of the alternative mRNAs are expressed in sex- or tissue-specific patterns that are compatible with regulation of tra-2 function through alternative RNA splicing.

Both males and females express tra- 2 mRNAs with an unblocked ORF in somatic tissues

One way in which alternative splicing might serve to regulate tra-2 function is suggested by studies on the tra and $S_{x l}$ genes (Boggs et al. 1987; Bell et al. 1988). Alternative splicing of RNA from these genes gives rise to functional products in female individuals where their activities are needed and nonfunctional products in male individuals where their activities are not needed. The usage of the alternative splice acceptors in the joining of exons 5 and 6 in tra-2 transcripts is of special interest in this regard. When the upstream acceptor site is used, as in the type D RNA structure, the long ORF is terminated just downstream from this site and does not contain a complete RNP-CS. Use of the downstream acceptor, as in type A, B, and C mRNAs, generates a long uninterrupted ORF that includes the RNP-CS /see the +2068 to +2100 region in Fig. 1). It is through such mechanisms, in which ORFs are blocked or not blocked, depending on the splicing pattern chosen, that the activities of the tra and $S x l$ genes are regulated.

If expression of a functional tra-2 product is controlled through use of alternative acceptors at the exon 5/exon 6 junction, then we might expect RNAs with an unblocked ORF (downstream acceptor) to be expressed in the female soma and male germ line and RNA with a blocked ORF (upstream acceptor) to be expressed in the male soma and female germ line.

To determine whether tra-2 mRNA with an unblocked ORF is made in a sex-specific or tissue-specific way, we performed a nuclease protection experiment with a single-stranded probe overlapping the two pos- 


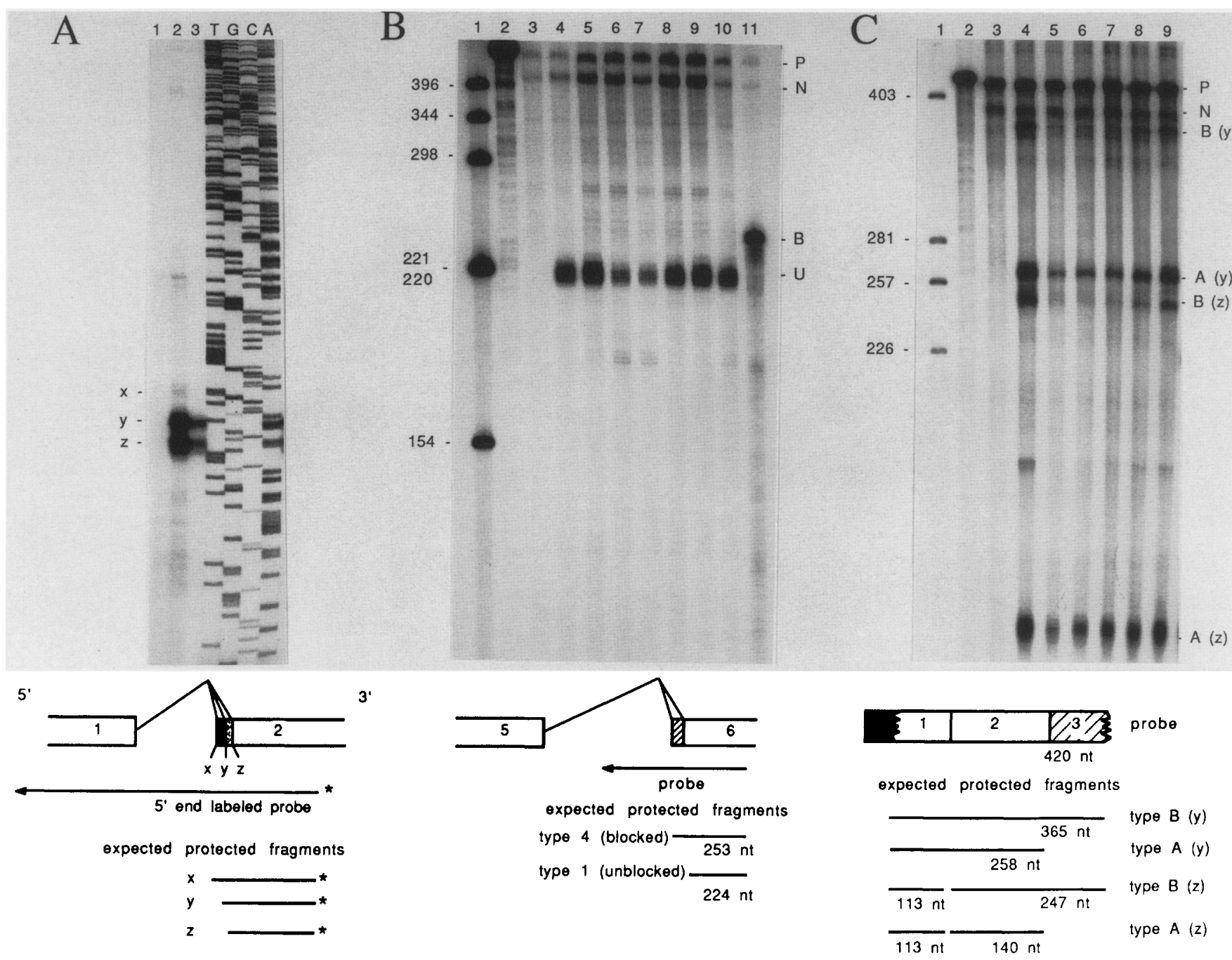

Figure 3. Expression of type A, B, and D transcripts in males and females. Nuclease protection experiments examining the distribution and usage of various tra-2 splicing alternatives are presented. (A) SI nuclease protection experiment comparing the usage of acceptors $\mathrm{x}, \mathrm{y}$, and $\mathrm{z}$ in splicing exon 1 to exon 2. Protection of a $5^{\prime}$-end-labeled single-stranded DNA probe extending from +982 to +1 with yeast tRNA (lane 1) and Drosophila adult female or male $A^{+}$RNA (lanes 2 and 3 ) is shown. Samples were electrophoresed adjacent to a sequence ladder produced by use of a primer coincident with the 5 ' end of the probe on a single-stranded template of the same region. The sequencing lanes are labeled so that the sequence may be read directly in the sense orientation. $(B)$ Mung bean nuclease protection experiment comparing splicing to alternative acceptors preceding exon 6 . Products from a pBR322 HinfI digest and the undigested uniformly labeled single-stranded DNA probe spanning the region between +2321 and +1891 are shown in lanes 1 and 2, respectively. Fragments of this probe protected by yeast RNA (lane 3), A+ RNA from adult females and males (lanes 4 and 5 ), from germ line-deficient adult females and males (lanes 6 and 7), and from third instar females and males (lanes 8 and 9) are shown. As controls, protected fragments extending to either acceptor site were generated by protecting the probe with unlabeled DNA from type A (lane 10) and type D (lane 11) cDNA clones. Bands on the gel correspond in size to the undigested probe (P), RNA using the upstream acceptor, which blocks the ORF (B), and the downstream acceptor, which leaves the ORF unblocked (U). An additional band (N) is obtained with both yeast and Drosophila RNA and therefore does not result from protection of the probe by any tra-2 RNA. $(C)$ S1 nuclease protection experiment examining expression of type A and B transcripts. Products of a pBR322 AluI digest are shown in lane 1. Lanes $2-9$ are as in $B$. Bands indicated on the gel correspond in size to the undigested probe $(P)$ and fragments protected by type $A$ and B RNAs using either the $y$ or $z$ acceptor sites in all combinations. In principle, bands labeled Ay and Az may also derive from type $\mathrm{D}$ transcripts, as may Ay and By derive from type $\mathrm{A}$ and $\mathrm{B}$ transcripts using the $\mathrm{x}$ acceptor site. However, as shown in $A$ and $B$, these splicing alternatives are expressed at very low levels and probably do not contribute meaningfully to this experiment.

sible acceptor sites (see Fig. 3B). In this experiment, we examined RNAs expressed in both adults and third instar larvae because tra-2 activity is known to be required for various aspects of sexual differentiation during both of these developmental stages (Baker and Ridge 1980; Ota et al. 1981; Belote and Baker 1982, 1987; Belote et al. 1985). To distinguish splicing patterns expressed in somatic tissues from those that are dependent on development of germ line tissues, we examined the splicing of tra-2 mRNA in individuals that are the adult progeny of tudor mothers. Both male and female progeny of tudor ${ }^{1}$ females lack germ cells but develop apparently normal 
somatic tissues (Boswell and Mahowald 1985). By comparing the expression of a particular mRNA in these germ line-deficient individuals to its expression in wildtype individuals, it is possible to determine whether that mRNA is expressed in the germ line or in the soma or both. One caveat of this approach is that mRNAs expressed only in somatic tissues that are dependent on germ line development may also be absent from tudor RNA preparations.

The nuclease protection experiment shown in Figure 3B demonstrates that in all of the RNA samples examined, only molecules in which the downstream acceptor site is used (unblocked ORF) are detected (band labeled U). This indicates that the downstream acceptor site is used at much higher frequency than the upstream acceptor in both adults (lanes 4 and 5) and third instar larvae (lanes 8 and 9) of either sex. The protected fragment corresponding to the downstream acceptor was detected in both male and female germ line-deficient individuals, indicating that mRNAs with an unblocked ORF are expressed in the soma of both sexes (lanes 6 and 7). Substantially higher levels of this protected fragment were obtained with RNA from both males and females containing a normal germ line /cf. lanes 4 and 5 to 6 and 7). This indicates that mRNAs using the downstream acceptor site are also expressed in germ line tissues (or germ line-dependent somatic tissues) in both sexes.

These results demonstrate that blockage of the long tra-2 ORF via alternative acceptor site selection at the exon 5/exon 6 junction is not regulated in a way that might account for the female-specific activity of the tra-2 gene in somatic tissues or its male-specific activity in the germ line. Rather, it appears that RNAs encoding an unblocked ORF are expressed in a non-sex-specific manner in both somatic and germ line tissue.

Transcripts with type $A$ and $B$ splicing patterns are not expressed in a sex-specific way, but those using the type $C$ pattern are male-specific

Another way in which tra-2 activity might be regulated is by sex-specific and tissue-specific expression of alternative mRNAs encoding protein isoforms that perform functions specific to either the female soma or the male germ line. To examine this possibility, we determined whether any of the tra-2 mRNAs that encode long ORFs (types A, B, and C) are specifically expressed in the female soma or in the male germ line.

To examine where type A and B splicing patterns are expressed, we performed a nuclease protection experiment on the same set of RNA preparations used in the previous section. In this case, however, we used a uniformly labeled probe that distinguishes between type A and $B$ RNAs. In addition, RNAs using the $y$ and $z$ acceptors near the beginning of exon 2 are expected to give different nuclease digestion patterns. Thus, four different combinations of splicing patterns $(\mathrm{Ay}, \mathrm{Az}, \mathrm{By}$, and $\mathrm{Bz}$ ) can be distinguished by the protection of differentsized fragments, as shown diagrammatically at the bottom of Figure 3C.
The results of this experiment show that all four combinations of splicing alternatives are expressed in both male and female individuals (Fig. $3 \mathrm{C}$ ). These RNAs are each expressed at higher levels in wild-type females than in males (lanes 4 and 5), but this difference is probably due to expression deriving from the female germ line because no difference in their levels was observed between male and female flies lacking a germ line (lanes 6 and 7). Therefore, none of these RNAs are enriched in the somatic tissues of females, as compared to males, nor are any of them expressed only in the male germ line.

Type A and type B RNAs do appear to differ somewhat in their relative distributions in the soma and germ line. Type A mRNAs are the predominant transcripts expressed in somatic tissues (cf. Ay and $\mathrm{Az}$ to $\mathrm{By}$ and $\mathrm{Bz}$ in lanes 6 and 7), whereas expression of type B mRNAs seems to be most prominent in the female germ line (cf. lanes 4 and 6). A female germ line-dependent component of tra-2 mRNA expression is consistent with the previous finding that tra-2 mRNA is transcribed at relatively high levels in ovaries (Amrein et al. 1988; Goralski et al. 1989).

The above findings indicate that expression of type $A$ or type B mRNAs is not confined only to those tissues where tra-2 is known to function; therefore, the splicing pathways leading to these RNAs are not regulated in a manner that could account for the sex-specific functioning of the tra-2 gene in either somatic sex determination or spermatogenesis.

We next examined the expression of type C mRNA. This RNA contains a 232-nucleotide segment located between exons 3 and 4 that is not present in the other tra-2 mRNAs (see Fig. 2). Therefore, we expected a probe containing sequences from within this segment to hybridize with type C RNA but not other tra-2 RNAs. Shown in Figure 4 is an RNA blot hybridization experiment using such a probe. A prominent band $\sim 1.7 \mathrm{~kb}$ in size) is detected in RNA from male adults but not females (Fig. 4). This band was absent in males lacking a germ line (see the lane labeled tudor male), suggesting that it is expressed in male germ cells. When RNA isolated from the testes and carcasses of wild-type adults was examined (Fig. 4) it was found that type C RNA was specifically expressed only in the testes consistent with an origin in the germ line.

To confirm that the $1.7-\mathrm{kb}$ band observed in the above experiment genuinely represents the expression of type C RNA, we examined the structure of this male-specific RNA by using nuclease protection analysis. In this experiment, we used an end-labeled single-stranded probe extending 845 nucleotides upstream from a position near the $3^{\prime}$ end of the retained 232 nucleotide intron. This probe is depicted in Figure 5A. It can be seen in lanes 3 and 4 of Figure 5A that a 331-nucleotide fragment was protected by RNA from males but not females. This fragment was not protected in males lacking germ line tissue, thus confirming that the 232-nucleotide intron is retained only in transcripts expressed in the male germ line for a germ line-dependent somatic tissue). This is fully consistent with the idea that the 


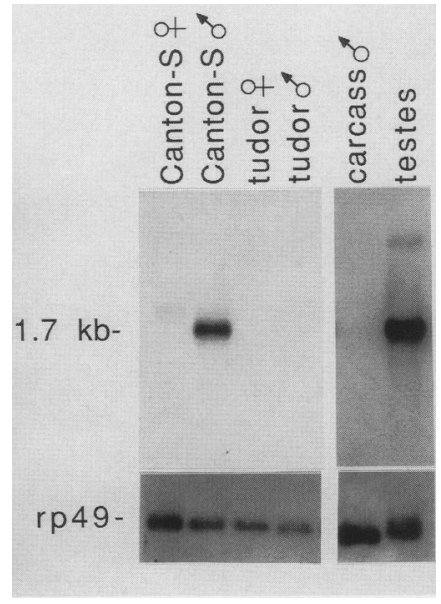

Figure 4. RNA blot hybridization to transcripts containing the 232-nucleotide intron. Blot hybridization experiment in which $1 \mu \mathrm{g}$ of $\mathrm{A}^{+}$RNA from wild-type (Canton-S) adult females and males and from germ line-deficient adult females and males (progeny of $t u d o r^{1}$ mothers) and RNA from 50 dissected wildtype male adult carcasses and testes is hybridized with labeled single-stranded DNA homologous to the 232-nucleotide intron. Position of the 1.7-kb band is indicated. (Bottom) Hybridization of same blot to a probe from the ribosomal protein 49 gene (O'Connell and Rosbash 1984) as a control for loading.

male germ line-specific mRNA detected above is of the type $\mathrm{C}$ structure. These results show that the retention of the 232-nucleotide intron in tra-2 transcripts is regulated in a tissue-specific and sex-specific way. The 179amino-acid polypeptide product encoded by the type C mRNA structure is therefore likely to be expressed only in the male germ line, suggesting that it serves a specialized role in the functioning of the tra-2 gene during spermatogenesis.

Taken as a whole, the above analysis of tra-2 transcripts suggests that sex-specific regulation of tra-2 activity differs in the soma and germ line. Whereas alternative RNA splicing may be responsible for the specific functioning of the tra-2 gene in the male germ line, we find no evidence of a role for alternative splicing of tra-2 transcripts in regulating female-specific sex determination function of the tra-2 gene in the soma.

RNA from a tra-2-lacZ fusion gene is translated in both males and females to produce a protein that is localized in the nucleus

The absence of a female-specific tra-2 transcript in the soma led us to wonder whether tra-2 activity might be sex-limited in somatic tissues through the regulation of translation. In the simplest version of this hypothesis, all forms of tra-2 mRNA would be translationally silent in male somatic tissues and translationally active in female somatic tissues. To test this simplest case and to determine whether the tissue distribution of tra-2 products is similar in males and females, we constructed a tra-2-lac $Z$ fusion gene by inserting a fragment containing $\sim 700$ nucleotides of upstream sequences, the tra-2 transcription initiation site (see below), and the amino-terminal segment of the tra-2 protein-coding region, including all three putative start codons into a Pelement transformation vector ( $\mathrm{pCaZPA}$ ), which already contains an enzymatically active segment of the Escherichia coli lacZ gene, the tra-2 polyadenylation signal, and the wild-type white $(w)$ gene as an independent marker (for details of constructions, see Experimental procedures and Fig. 6A). The resultant plasmid (pCaZPA-1,2,3) was introduced into embryos of the $w^{1118}$ strain by microinjection, and transformed $G_{1}$ individuals were detected by their expression of $w^{+}$eye pigmentation. Thirteen independent $w^{+}$lines were obtained and maintained as homozygous or balanced stocks.

Similar patterns of X-gal staining were obtained from each of the 13 transformed lines. The adults and third instar larval patterns are summarized in Table 1. Identical sets of somatic tissues were stained in males and females in each line, demonstrating that at least some of the fusion gene mRNA is expressed and translated in both sexes. This suggests that translation of tra-2 mRNA is not absolutely regulated in a sex-specific way in somatic tissues. Both ovaries and testes were prominently stained in patterns that suggest tra-2 mRNA is translated in the male and female germ line tissues as well.

A striking feature of the $l a c Z$ expression pattern observed in each of the transformed lines /using either anti- $\beta$-galactosidase antibody or X-gal staining/ was its nuclear localization (see Fig. $6 \mathrm{~B}, \mathrm{C}$ ). The localization of the tra-2-lacZ fusion protein in the nucleus shows that sequences originating from the tra-2-coding region can specify nuclear localization and suggests that the tra-2 product is normally transported into the nucleus.

The tra-2 gene has multiple transcription start sites, one of which is male specific and germ line-dependent

In addition to providing data on the distributions and splicing patterns of tra-2 transcripts, our nuclease protection experiments gave us information suggesting the existence of multiple transcription start sites. In particular, the data from these experiments suggest that tra-2 transcripts initiate in two distinct regions. The downstream region appears to be used exclusively in the male germ line to produce type C RNA (and a related RNA described below), whereas the upstream region appears to be used in both males and females to produce RNA types A, B, and D.

With respect to the transcription start site of type $C$ RNA, there are two observations suggesting that it is located in the middle of exon 3 near nucleotide +1112 . First, in the nuclease protection experiment in Figure $5 \mathrm{~A}$, the probe used was cleaved at this location (see Fig. $5 \mathrm{~A}$ ), indicating a discontinuity between type C RNA and the genomic DNA sequence. This discontinuity could reflect either the position of the type C RNA $5^{\prime}$ terminus or the position of a previously undiscovered splice junction in type C RNA. However, the latter possibility 


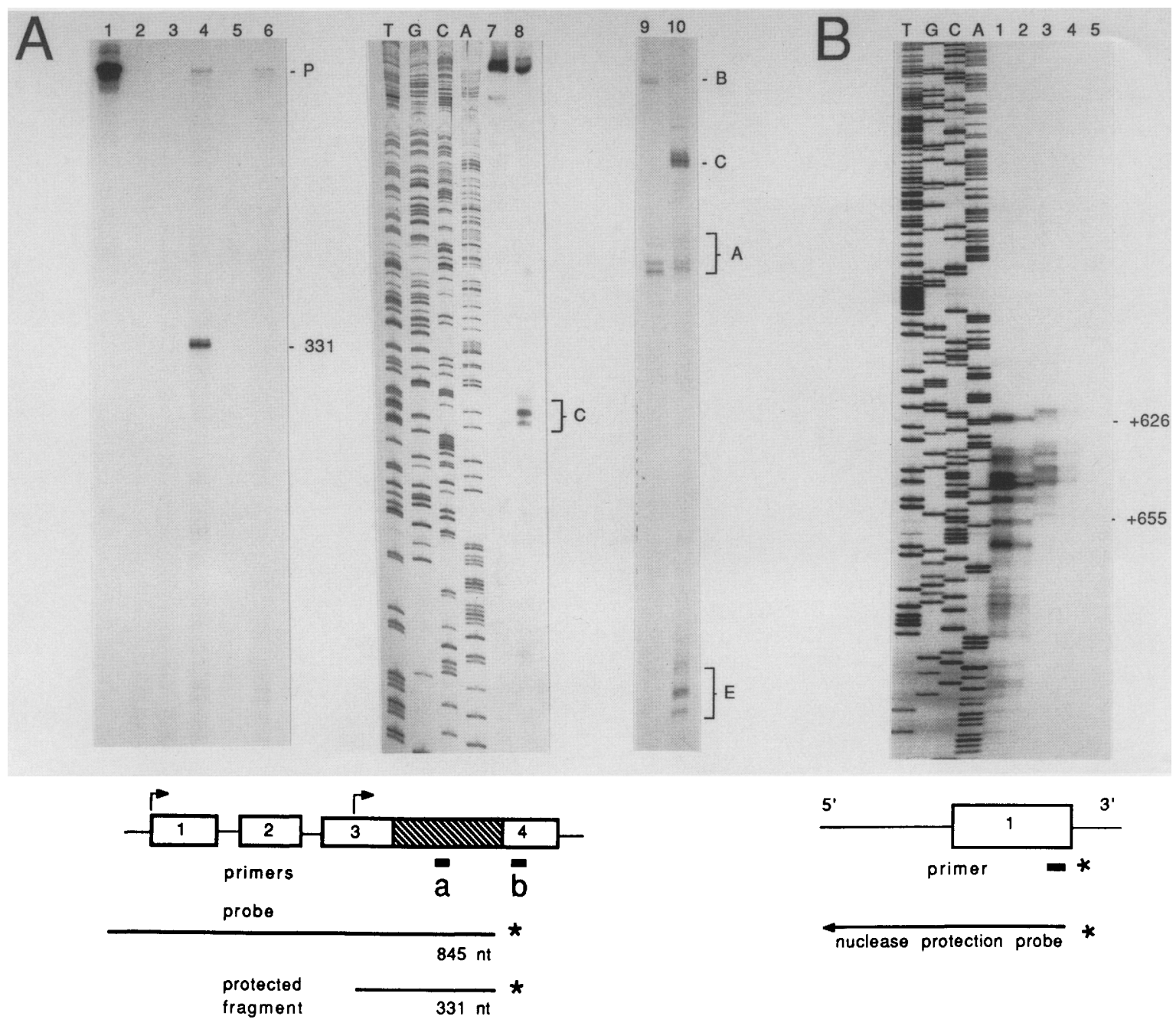

Figure 5. Alternative splicing patterns and transcription start sites used in the male germ line. $\{A \mid$ Experiments examining the sex and tissue specificity of type $C$ and $E$ transcripts. (Left) A mung bean nuclease protection experiment in which individual lanes contain either undigested 845-nucleotide probe (lane 1) or probe protected with yeast tRNA (lane 2), $A^{+}$RNA from adult females and males (lanes 3 and 4), or germ line-deficient adult females and males (lanes 5 and 6). The positions of bands corresponding in size to undigested probe $(\mathrm{P})$ and the expected 331-nucleotide protected fragment from type $\mathrm{C}$ transcripts are indicated. (Center) A sequencing ladder generated with primer a adjacent to a primer extension experiment done with the same primer and adult female (lane 7) or adult male (lane 8) $\mathrm{A}^{+}$RNA. Sequencing lanes are labeled to be read in the sense orientation. Extension products from type C transcripts terminating near +1112 are indicated. (Right) Products of a primer extension experiment done with primer $\mathrm{b}$ and either adult female (lane 9) or adult male (lane 10) $\mathrm{A}^{+}$RNA. Products corresponding to type A, B, C, and E transcripts are indicated. (B) Parallel S1 nuclease and primer extension experiments mapping the multiple non-sex-specific transcription start sites between +626 and +655 . A primer near the $3^{\prime}$ end of exon 1 was used both in sequencing reactions on cloned template and in primer extension reactions on both adult female (lane 1) and male (lane 2) $\mathrm{A}^{+}$RNAs. S1 nuclease protection experiment in which a probe generated with same end-labeled primer is protected with adult female or male $A^{+}$RNA (lanes 3 and 4) or yeast RNA (lane 5) and electrophoresed in parallel. Sequencing lanes are labeled to be read in sense orientation. Products appearing in both S1 nuclease and primer extension experiments must represent a bona fide $5^{\prime}$ termini.

seems unlikely because no AG dinucleotide, which is normally found at a 3' splice site (Breathnach et al. 1978; Oshima and Gotoh 1987), is found in the tra-2 gene's DNA sequence at the site of the discontinuity /the closest AG dinucleotide is located 10 nucleotides upstream). A second reason for believing that this site may represent the $5^{\prime}$ end of type C RNA is that the longest sequenced type $\mathrm{C}$ cDNA clone terminates at precisely this site (T.J. Goralski and B.S. Baker, unpubl.).
To determine whether the $5^{\prime}$ end of type C RNA is located at the site of the above-mentioned discontinuity, we performed a primer extension experiment. The oligonucleotide primer that we selected is homologous to sequences within the 232-nucleotide intron that is found only in type C RNA (primer a in Fig. 5A). The extension products obtained should therefore originate only from type C RNA; the results are shown in lanes 7 and 8 of Figure 5A. The major product synthesized with 

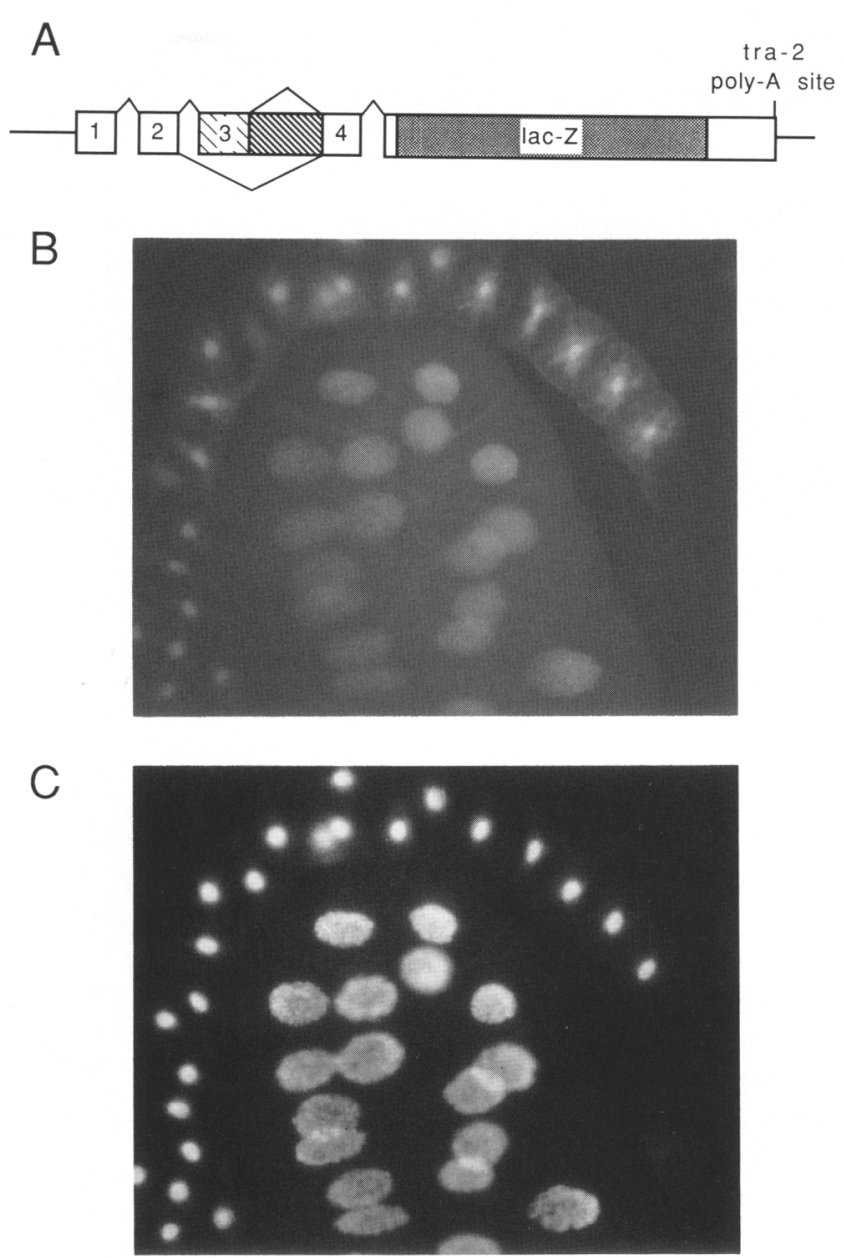

Figure 6. Nuclear localization of tra-2-lacZ fusion protein. $(A)$ tra-2-lacZ fusion gene. Open boxes are tra-2 exon sequences. Lines are tra-2 introns or flanking sequences. Crosshatched box indicates regions affected by alternative splicing. Stippled region denotes lac $Z$ sequences. $(B)$ Staining with mouse anti- $\beta$ galactosidase and FITC-conjugated goat anti-mouse antibodies of tissue from a larva carrying the fusion gene. Large nuclei are in salivary gland cells, whereas smaller nuclei are in fat body cells. $(C)$ Staining of the same tissue with the nuclear stain bisbenzimide.

male RNA is exactly the size expected if the $5^{\prime}$ end of type $\mathrm{C}$ mRNA is located within exon 3 at +1112 . Two minor products, corresponding to termini at +1109 and +1115 , were also obtained. This result confirms that the previously observed nuclease cleavage near +1112 reflects the $5^{\prime}$ terminus of type C mRNA and not a splice junction. Because the $5^{\prime}$ terminus of mRNAs generally coincides with the site of transcription initiation (Ziff and Evans 1978), we interpret this result to mean that transcription of type C mRNA molecules is initiated at this site.

Additional nuclease protection experiments that were performed in the course of mapping the type C mRNA $5^{\prime}$ termini (data not shown) suggested the existence of an additional tra-2 transcript that is expressed specifically in the male germ line and initiates near +1112 . This transcript differs from the type $\mathrm{C}$ structure in that it
Table 1. Summary of $X$-gal staining patterns

\begin{tabular}{|c|c|c|}
\hline Larval tissues & Males $^{a}$ & Females $^{a}$ \\
\hline Salivary glands & ++ & ++ \\
\hline Pharynx & ++ & ++ \\
\hline Brain & + & + \\
\hline Esophagus & ++ & ++ \\
\hline Fat bodies & ++ & ++ \\
\hline Caeca & ++ & ++ \\
\hline Imaginal discs & +++ & +++ \\
\hline Proventriculus & ++ & ++ \\
\hline Malpighian tubules & ++ & ++ \\
\hline Hindgut & ++ & ++ \\
\hline Trachea & $++1-$ & $++1-$ \\
\hline Muscle & - & - \\
\hline Epidermis & ++ & ++ \\
\hline Testes & +++ & NA \\
\hline Ovaries & NA & +++ \\
\hline Adult tissues & Males $^{\mathbf{a}}$ & Females $^{\mathrm{a}}$ \\
\hline Brain & $++1+$ & $++1+$ \\
\hline Eye & + & + \\
\hline Fat body & + & + \\
\hline Heart & - & - \\
\hline Crop & - & - \\
\hline Malpighian tubules & ++ & ++ \\
\hline Rectum & + & + \\
\hline Ventriculus & + & + \\
\hline Muscle & - & - \\
\hline Seminal vesicle & + & NA \\
\hline Accessory gland & $+1-$ & NA \\
\hline Testes & $+t+$ & NA \\
\hline Ovaries & NA & +++ \\
\hline
\end{tabular}

a $+1++,+/-)$ Variable staining; (NA) not applicable.

does not contain the 232-nucleotide intron. To confirm the existence of an RNA with this structure, we performed another primer extension experiment with an oligonucleotide primer homologous to sequences from within exon 4 (primer b in Fig. 5A). In contrast to primer a used in the previous primer extension experiment (Fig. $5 \mathrm{~A}$ ), which annealed only to type $\mathrm{C}$ mRNA, primer $\mathrm{b}$ is expected to anneal with all tra-2 mRNAs including those lacking the 232-nucleotide intron. As shown in lanes 9 and 10 of Figure 5A, male-specific extension products are obtained of the sizes expected from transcripts in which the 232-nucleotide is removed and that initiate at the same three sites $(+1109,+1112,+1115)$ as type C RNA (see bands labeled E), thus confirming the existence of this second type of male-specific transcript. We do not know the complete structure of this "spliced" male-specific RNA, but because it clearly differs in structure from types $A, B, C$, and D, we will refer to it is as type $\mathrm{E}$. In nuclease protection experiments, a fragment corresponding to first exon in the type $\mathrm{E}$ transcripts is protected only by RNA from males containing a normal germ line, indicating that this transcript is probably male germ line-specific (data not shown).

As expected, male-specific primer extension products corresponding to type $\mathrm{C}$ transcripts were also detected in the above experiment (bands labeled C in Fig. 5A, lane 
10). Comparison of the steady-state levels of type $C$ and $\mathrm{E}$ molecules in poly $(\mathrm{A})^{+}$RNA detected by either the primer extension (see Fig. 5A, lane 10) or nuclease protection assays (not shown) reveals that type $\mathrm{C}$ is about two to three times more abundant than type $\mathrm{E}$. The 232nucleotide intron is therefore present in a majority of those transcripts that initiated at the male germ linespecific start sites within exon 3 .

It seems tempting to view type C RNA as a slowly spliced precursor of type E RNA. If this were the case, we would expect type E transcripts to be resolved from other tra-2 transcripts in RNA blot hybridization experiments as a result of their smaller size; however, no smaller transcripts are observed in such experiments (Goralski et al. 1989). The most likely explanation for this is that type E transcripts are not merely products that result from removal of the 232-nucleotide intron from type $\mathrm{C}$ transcripts but instead are of a different structure containing additional sequences not present in type C RNA. These sequences would compensate in size for the spliced 232-nucleotide intron. An alternative explanation is that type $\mathrm{E}$ transcripts are products of type C RNAs that have an unusually low mobility (for their size) on formaldehyde gels.

Type $A$ and $B$ transcripts initiate at a heterogeneous set of non-sex-specific transcription start sites

We then examined the position and usage of the upstream transcription start site. In the above primer extension experiment, several non-sex-specific products were obtained in addition to the products representing the male-specific type $\mathrm{C}$ and type $\mathrm{E}$ mRNAs (see bands labeled A and B in lanes 9 and 10 of Fig. 5A). These products are of the sizes expected, based on the structures of tra-2 cDNA clones, to derive from type A and type B transcripts initiating at sites near the $5^{\prime}$ end of exon 1, 500 nucleotides upstream of male-specific start sites.

To confirm the presence of non-sex-specific transcription start sites in this region, we again employed a combination of nuclease protection and primer extension analyses. For primer extension we used an end-labeled oligonucleotide primer homologous to sequences in exon 1. For nuclease protection, a single-stranded probe was end-labeled at precisely the same site as the oligonucleotide (see schematic in Fig. 5B). Both types of analysis gave a similarly sized set of products (cf. lanes 1 and 2 to 3 and 4 in Fig. 5B), indicating the presence of a multitude of non-sex-specific transcription start sites in the region between +626 and +655 (the nuclease protected fragments in lanes 3 and 4 are $2-4$ nucleotides longer than the corresponding primer extension products in lanes 1 and 2 due to steric hindrance caused by the mRNA cap structure). Similar primer extension experiments performed with primers located in exons 2 and 3 confirmed this result and revealed no additional start sites (data not shown). The simplest interpretation of these experiments is that tra-2 transcripts initiate at this set of upstream transcription start sites in both sexes and are subsequently spliced to form either type $\mathrm{A}$ or type B RNAs.

The above results reveal an intriguing correlation between the site at which transcription initiates and splicing of the 232-nucleotide intron between exons 3 and 4 . This intron is efficiently removed from those premRNAs that are expressed in somatic tissues and are initiated at the upstream set of transcription start sites. As a result, the predominant RNAs found /types A and $B$ ) in these tissues do not contain this intron. In contrast, in the male germ line, the majority of transcripts initiating at the downstream transcription start sites within exon 3 retain the 232-nucleotide intron. Because the different transcription start sites (and splicing patterns) are used in different tissues, it is not known whether the efficiency with this intron is spliced is an indirect consequence of the location of the pre-mRNA $5^{\prime}$ terminus or whether splicing efficiency is determined by tissuespecific factors that directly control splicing (see Discussion).

The existence of two separate sets of transcription start sites that are utilized in a tissue-specific way suggests that each set is associated with a distinct promoter. A search of the sequences flanking each of these start sites revealed no identities with the TATAA box consensus sequence that is characteristic of many eukaryotic promoters (Goldberg 1979). Two similar sequences, CATAA and TAAAT, are located 14 and 33 nucleotides, respectively, upstream of the first transcription site $(+626)$. The lack of a good TATAA sequence may be the cause of heterogeneous initiation at both the upstream and downstream sites because several other genes lacking consensus TATAA sequences are also known to exhibit such heterogeneity (Baker et al. 1979; Flavell et al. 1979; Grosschedl and Birnstiel 1980; Allan et al. 1983; Reynolds et al. 1984).

\section{Discussion}

Genetic and molecular analysis of the tra-2 gene has revealed that it has two apparently distinct sex-specific functions that are both limited to specific tissues. In somatic tissues of chromosomally female individuals, tra-2 function is required for splicing of the $d s x$ premRNA in its female-specific pattern, whereas in the germ line of male individuals, it is required for some essential process in spermatogenesis, the molecular nature of which is unknown. Extensive genetic analysis of tra-2 loss-of-function mutations has revealed no role for this gene in either the male soma or the female germ line.

Although each of these functions had been studied extensively using classical genetic approaches (Fujihara et al. 1978; Baker and Ridge 1980; Belote and Baker 1982, $1983,1987)$, very little was known about the molecular basis of their regulation or their relationship to one another (e.g., whether both functions are executed by a single gene product or by different products from a single gene). The molecular studies presented here indicate that the tra-2 gene expresses multiple transcripts that differ in structure due to the usage of multiple transcrip- 
tion start sites, alternative splicing patterns, and multiple polyadenylation sites. Among these transcripts, we have identified four types $(A, B, C$, and D) that differ with respect to the proteins that they encode. A fifth type of RNA was also found (type E), but not completely characterized, that may encode another tra-2 protein. Although type A, B, C, and E transcripts were readily detected in nuclease protection experiments, type $D$ transcripts were not detected, indicating that they expressed at very low (undetectable) levels. In agreement with this, type $D$ transcripts are represented by only 1 of the 16 tra-2 cDNA clones that have been sequenced (Amrein et al. 1988; Goralski et al. 1989; T.J. Goralski and B.S. Baker, unpubl. and this paper). On the basis of the experiments presented here, as well as a number of nuclease protection experiments that were not presented (W. Mattox, unpubl.), we believe that no other varieties of tra-2 transcripts are found in the adult fly at substantial levels.

Although two tra-2 transcripts were found only in the male germ line, suggestive of a specific role for them in spermatogenesis, no sex-specific transcripts that might be responsible for the female-specific functioning of the tra-2 gene in sex determination were found in the soma. These patterns of expression (summarized in Table 2) suggest that the male germ line and somatic sex determination functions of the tra-2 gene are regulated in different ways.

Products of the tra-2 gene are expressed in both female and male somatic tissues but are inactive in males due to the absence of the female-specific tra gene product

Data available previous to the work reported here were compatible with either of two hypotheses for the regulation of the tra-2 sex determination function in somatic tissues (McKeown et al. 1988; Nagoshi et al. 1988; Belote et al. 1989). One view held that one or more polypeptides encoded by the tra-2 gene is expressed only in females and that synthesis of this female-specific tra-2 product is positively regulated by the female-specific product of the tra gene. The alternative view was that identical tra-2 products are synthesized in males and females but they only function to direct splicing of $d s x$ mRNA along with the female-specific pathway when the female-specific tra product is present.

Table 2. Distribution of tra-2 transcripts

\begin{tabular}{lcccc}
\hline Type & $\begin{array}{l}\text { Female } \\
\text { soma }\end{array}$ & $\begin{array}{l}\text { Male } \\
\text { soma }\end{array}$ & $\begin{array}{l}\text { Female } \\
\text { germ line }\end{array}$ & $\begin{array}{l}\text { Male } \\
\text { germ line }\end{array}$ \\
\hline A & ++ & ++ & + & $\star^{\mathrm{a}}$ \\
B & + & + & ++ & $\star^{\mathrm{a}}$ \\
C & - & - & - & +++ \\
E & - & - & - & + \\
\hline
\end{tabular}

a/*) Germ line expression is inferred from differences in amounts found in strains with and without germ tissue. Although no differences were observed in these cases, a low level of transcript may have been missed due to the high background from somatic expression.
To discriminate between these possibilities, we examined the expression of each type of tra-2 transcript in the somatic tissues of males and females. Both of the tra-2 mRNAs detected in the somatic tissues of adult flies are expressed at equal levels in males and females. Simply interpreted, this means that tra-2 pre-mRNA splicing in the soma is not regulated in a sex-specific way. Furthermore, the finding that a tra-2-lacZ fusion gene is expressed in both male and female somatic tissues suggests that tra-2 mRNAs are normally translated into polypeptides in both the male and female soma. It therefore seems improbable that tra or any other genes in the sex determination hierarchy act to regulate the femalespecific activity of the tra-2 gene by controlling the synthesis of a female-specific tra-2 RNA or polypeptide. Rather, it seems that non-sex-specific tra-2 products are somehow "activated" by the presence of the functional tra product in females, whereas tra-2 products are unable to function due to the absence of a tra product in males.

This idea is strongly supported by the observation that when the tra female-specific product is expressed ectopically in chromosomally male individuals, they develop as females in which $d s x$ RNA is spliced in the femalespecific pattern (McKeown et al. 1988). The feminization of chromosomal male individuals observed in these experiments was dependent on the presence of a functional tra-2 gene, as may be expected if the ectopic tra product induces $d s x$ female splicing through the action of the tra-2 products that are present in these chromosomal males. Taken together with our findings, these results indicate that tra-2 products are normally present in males but are quiescent due to the absence of the tra function. The nature of the interaction between tra and tra-2 products is unknown and might be mediated directly through a physical interaction or indirectly through the activities of other components.

Although the above arguments explain how tra-2 activity is sex-limited in somatic tissues, they do not account for why tra-2 products should be present in the male soma where they normally serve no apparent purpose. One possibility is that "wasted" synthesis of tra-2 products in males is simply less costly than the means required to regulate tra-2 expression in a sex-specific way (Belote et al. 1989). Other possibilities are that tra-2 products normally execute some function in the male soma that has eluded detection or that is not affected by the mutant alleles currently available. Such a function may have a more general role in RNA processing or may serve to regulate specific alternative splicing choices outside the sex determination regulatory hierarchy.

\section{Alternative tissue-specific splicing patterns and an alternative transcription start site are used in the expression of male-specific tra- 2 mRNAs}

In contrast to the situation in somatic tissues where the expression of tra-2 transcripts does not correspond with the sex-specific nature of tra-2 function, two tra-2 transcripts (types $\mathrm{C}$ and $\mathrm{E}$ ) are expressed in the germ line in a 
pattern that corresponds to the male-specific activity of the tra-2 gene. This raises the possibility that the malespecific function of the tra-2 gene is dependent on the tissue- and sex-specific regulatory mechanisms that govern the expression of these RNAs.

The two male germ line-specific tra-2 RNAs share a common site of transcription initiation that is downstream from the sites used for initiation of other tra-2 transcripts. One of these transcripts (type $\mathrm{C}$ ) also differs from all other tra-2 RNAs in that it contains a 232-nucleotide sequence that forms all or part of an intron in other tra-2 RNAs. This mRNA is the most abundant tra-2 transcript present in the male gonad. Recent germ line transformation experiments with tra-2-lacZ fusion gene constructs suggest that type $C$ transcripts function as normal mRNA molecules that are translated in the testes (W. Mattox, unpubl.). As noted above, type C RNA encodes a polypeptide of 179 amino acids that contains an RNP-CS, suggesting that tra-2 may also play a role in RNA metabolism in the male germ line.

There are several possible mechanisms by which the alternative splicing of tra-2 pre-mRNA in the male germ line might be regulated. For instance, trans-acting regulatory molecules that are specific to the male germ line could act directly to repress splicing of the 232-nucleotide intron. Alternatively, trans-acting regulatory factors in other tissues might expedite removal of this intron. Mechanisms involving germ line-specific or somatic line-specific trans-acting regulatory factors have also been suggested for the regulation of the germ line-specific splicing of transcripts from the P-element transposon (Laski et al. 1986). As with tra-2 transcripts, the splicing of P-element transcripts involves a choice between the retention or removal of an intron located within the protein-coding region. Recent studies have identified sequences near the $5^{\prime}$ and $3^{\prime}$ splice junctions flanking this intron that tissue-specific factors might recognize during its splicing (Laski and Rubin 1989). There are no striking similarities between these sequences and those within or flanking the regulated tra-2 intron; however, it should be noted that in the case of the P-element transcripts, the intron in question is removed in the germ line and retained in somatic tissues. This is opposite to the situation with tra-2.

Another possibility is that regulation of alternative splicing of tra-2 pre-mRNA is controlled indirectly through the tissue- and sex-specific use of the downstream transcription initiation site. The sequences located between the upstream and downstream transcription start sites ( $\sim 500$ nucleotides) are probably not included in precursors of the male germ line-specific transcripts but are found in those tra-2 transcripts that are expressed in tissues other than the male germ line. In several other gene systems, cis-acting sequences needed for properly regulated splicing have been found in nearby exonic sequences (Reed and Maniatis 1986; Mardon et al. 1987; Barone et al. 1989; Hampson et al. 1989; Laski and Rubin 1989; Nagoshi and Baker 1989; Streuli and Saito 1989). In the case of tra-2, the presence or absence of sequences upstream to the male germ line-specific start site within a pre-mRNA may influence, for instance, the efficiency with which the 232-nucleotide intron is removed. In this way, the utilization of different splicing pathways would be controlled indirectly by whatever factors regulate the differential selection of transcription start sites in the male germ line and in other tissues.

\section{Alternative tra-2 mRNAs encode several structurally distinct polypeptides that may play direct roles in regulating RNA splicing choices}

The four classes of tra-2 mRNAs encode a set of distinct but overlapping polypeptides. These polypeptides each have structural features that suggest they play a role in RNA splicing. All four conceptual polypeptides contain at least one of two segments within the tra-2-coding region that are particularly rich in arginine and serine (encoded by nucleotides +1495 to +1557 and +2287 to +2548 ; see Figs. 1 and 2). Similar arginine/serine-rich regions are found in the products of tra and suppressorof-white apricot genes (Boggs et al. 1987; Chou et al. 1987), which are known to regulate alternative splicing decisions (Zachar et al. 1987; Nagoshi et al. 1988). A similar highly charged region rich in arginine and serine is also found in the $70 \mathrm{~K}$ U1 small nuclear ribonucleoprotein (snRNP) protein (see below) (Theissen et al. 1986).

In addition, three of the four conceptual tra-2 polypeptides contain a complete RNP-CS (Dreyfuss et al. 1988). RNP-CS sequences are also found in a number of proteins that are involved in RNA processing, including heterogeneous RNP (hnRNP) proteins (Choi et al. 1986; Swanson et al. 1987; Merrill et al. 1988; Merrill and Williams 1990), poly(A)-binding protein (Adam et al. 1986; Sachs et al. 1986), and several small nuclear RNP (snRNP) proteins (Sillekans et al. 1987; Query et al. 1989|. It is particularly worth noting that the $S x l$ gene which, like tra-2, is known to regulate alternative splicing decisions within the Drosophila sex determination regulatory hierarchy, contains two sequences with similarity to the RNP-CS (Bell et al. 1988).

Studies on several proteins have provided evidence that the polypeptide domain encoded by the RNP-CS is directly involved in RNA binding (Sachs et al. 1986; Merrill et al. 1988; Query et al. 1989; Merrill and Williams 1990). Particularly illuminating is the recent work on the $70 \mathrm{~K}$ U1 snRNP protein which, like the tra-2 products, contains both an RNP-CS and arginine/serinerich regions. This protein makes up part of the U1 snRNP that is known to play an essential role in RNA splicing (Yang et al. 1981; Padgett et al. 1983; Kramer et al. 1984). Query et al. (1989) found that a 111-amino-acid region, which includes the RNP-CS of the $70 \mathrm{~K} \mathrm{U1}$ snRNP protein, but not its arginine/serine-rich regions, is sufficient for binding to the U1 snRNA. This finding indicates that the RNP-CS encodes an RNA-binding site and that the arginine/serine-rich region is unnecessary for U1 snRNA binding. However, a role for the arginine/ serine-rich region in interactions with pre-mRNAs or other splicing components is not ruled out. 
The finding that tra-2 proteins have similarities to known RNA-binding proteins led to the suggestion that tra-2 product(s) may interact directly with $d s x$ premRNA as part of the female-specific $d s x$ pre-mRNA splicing reaction (Amrein et al. 1988; Baker et al. 1989; Goralski et al. 1989). If this is so, then tra-2 proteins are likely to be located in the cell nucleus. Our finding that tra-2 sequences serve to direct a tra-2-lacZ fusion protein into the nucleus suggests that tra-2 polypeptides contain sequences that can expedite their transport into the nucleus.

It is interesting to note that the alternative splicing of tra-2 pre-mRNA gives rise to transcripts encoding products with several different combinations of the RNP-CS and arginine/serine-rich regions. Of the two arginine/serine-rich regions, one is located downstream of the RNP-CS and the other just upstream from it /see Fig. 2). The polypeptides encoded by type A and type B mRNAs include both of the arginine/serine-rich regions, as well as the RNP-CS, whereas the polypeptide encoded by type C mRNA contains only the downstream arginine/serine-rich region and the RNP-CS. Type D mRNA, which is expressed at very low levels, includes only the upstream arginine/serine-rich region. It is possible that through different combinations of these structural motifs, the different tra-2 products each play separate roles in RNA metabolism.

The results recently obtained by T.J. Goralski and B.S. Baker (unpubl.) are of particular interest with regard to the notion that different tra-2 proteins may serve different functions. Using the $h s p 70$ gene promoter to express RNA from different tra-2 cDNAs, they found that individual tra-2 products can complement the defects caused by apparent tra-2 null mutations even in tissues where they are not normally expressed. For instance, ectopic expression in the soma of RNA from a cDNA that can only be translated into the product normally encoded by the male germ line-specific type $C$ transcript can rescue the somatic sex determination defect. Conversely, the type A product, when expressed in the germ line, can rescue the male fertility defect. Although it must be kept in mind that these results could be attributable, in part, to the abnormally timed and higher than normal levels of expression that result from use of the hsp 70 promoter, they imply that the molecular functions of the various tra-2 products are closely related to one another. It seems most plausible that the structural differences in tra-2 polypeptides that result from alternative splicing of tra-2 mRNA serve to "fine tune" these products to perform their specific roles optimally.

\section{Experimental procedures}

Isolation and sequence analysis of phage CDNA clones

Twenty-six phage clones homologous to various tra-2 DNA fragments were isolated from a $\lambda$ gt 10 third instar larval imaginal disc cDNA library (provided by A. Cowman) by plaque hybridization (Benton and Davis 1977). The cDNA inserts of each were then subcloned into plasmids and restriction mapped. Preliminary sequence analysis of these clones, in which 100-200 nucleotides of sequence from the $5^{\prime}$ and $3^{\prime}$ ends of the cDNA inserts were determined allowed us to identify 10 clones that must each be of independent origin (i.e., they each differed from other clones by the insert end points, single nucleotide polymorphisms, or the pattern of splicing). These 10 cDNA inserts, as well as the 1.7-kb BgIII and 2.2-kb BglIIEcoRI fragments that encompass the tra-2 gene, were sequenced in their entirety by the methods of Sanger et al. (1977) and Mizusawa et al. (1986) by use of the exonuclease III deletion strategy (Henikoff 1984). In some cases, oligonucleotides identical to sequences from within the tra-2-coding region were used as primers for sequencing reactions. Computer resources for sequence analysis were provided by the BIONET National Computer Resource for Molecular Biology.

\section{Nuclease protection analysis}

Drosophila poly(A) ${ }^{+}$RNAs $(4-8 \mu \mathrm{g})$ were coprecipitated with 4 ng of gel-isolated single-stranded ${ }^{32} \mathrm{P}$-labeled DNA probes. The pellets were suspended in $25 \mu \mathrm{l}$ of $80 \%$ formamide, $400 \mathrm{mM}$ $\mathrm{NaCl}, 40 \mathrm{~mm}$ PIPES ( $\mathrm{pH} 6.8$ ), and $1 \mathrm{mM}$ EDTA and were subsequently incubated at $80^{\circ} \mathrm{C}$ for $1 \mathrm{~min}$ and then at $42^{\circ} \mathrm{C}$ for between 8 and $16 \mathrm{hr}$. S1 nuclease digestions were performed by adding $0.3 \mathrm{ml}$ of a solution containing $300 \mathrm{~mm} \mathrm{NaCl}, 30 \mathrm{~mm}$ sodium acetate $(\mathrm{pH} 4.5), 10 \mathrm{mM} \mathrm{ZnCl}_{2}$, and $80 \mathrm{U} / \mathrm{ml} \mathrm{S1} \mathrm{nu-}$ clease (Sigma) to the hybridization mixture and incubating at room temperature for $30 \mathrm{~min}$. Mung bean nuclease digestions were performed by adding $0.3 \mathrm{ml}$ of a solution containing 100 $\mathrm{mM} \mathrm{NaCl}, 30 \mathrm{~mm}$ sodium acetate $(\mathrm{pH} 4.5), 10 \mathrm{~mm} \mathrm{ZnCl}$, $0.001 \%$ Triton X-100, and $400 \mathrm{U} / \mathrm{ml}$ mung bean nuclease (Pharmacial to the hybridization and incubating at $37^{\circ} \mathrm{C}$ for $1 \mathrm{hr}$. The reactions were terminated by adding $0.1 \mathrm{ml}$ of $10 \mathrm{mM}$ Tris $\langle\mathrm{pH}$ 8.5 ), $0.5 \%$ SDS, $50 \mathrm{~mm}$ EDTA, and $20 \mu \mathrm{g} / \mathrm{ml}$ yeast tRNA (Boehringer), and the products were precipitated with 2 volumes of ethanol. Pellets were suspended in $60 \%$ formamide loading buffer, denatured, concentrated at $80^{\circ} \mathrm{C}$ for $10 \mathrm{~min}$, and electrophoresed on polyacrylamide/urea gels.

\section{Primer extension mapping of RNA $5^{\prime}$ ends}

Oligonucleotide primers were $5^{\prime}$-end-labeled with ${ }^{32} \mathrm{P}$ with $\mathrm{T} 4$ polynucleotide kinase (New England Biolabs). About $1 \mathrm{ng}$ of labeled primer was combined with $8 \mu \mathrm{g}$ of Drosophila poly(A) ${ }^{+}$ RNA in $30 \mu \mathrm{l}$ of a solution containing $1 \mathrm{M} \mathrm{NaCl}, 100 \mathrm{mM}$ PIPES (pH 6.8), $2.5 \mathrm{~mm}$ EDTA, and 0.05\% SDS and annealed for $8 \mathrm{hr}$ at $42^{\circ} \mathrm{C}$. Annealed primer and RNA were then precipitated with $400 \mu \mathrm{l}$ of $250 \mathrm{~mm}$ sodium acetate and $400 \mu \mathrm{l}$ of isopropanol for $30 \mathrm{~min}$ at $0^{\circ} \mathrm{C}$. Pellets were resuspended in $30 \mu \mathrm{l}$ of a solution containing $50 \mathrm{mM}$ Tris (pH 8.3), $60 \mathrm{mM} \mathrm{NaCl}, 6 \mathrm{mM} \mathrm{MgCl}_{2}, 10$ $\mathrm{mM}$ DTT, $5 \mu \mathrm{g} / \mathrm{ml}$ actinomycin D, and $0.5 \mathrm{~mm}$ dNTPs. Twenty units of RNasin (Promega) and 10 units of AMV reverse transcriptase (Seikagaku-America) were then added, and the reaction mixture was incubated at $42^{\circ} \mathrm{C}$ for $60 \mathrm{~min}$. The samples were then phenol-extracted and ethanol-precipitated. Resuspension and electrophoresis were carried out as described for nuclease protection analysis.

\section{Construction of $p C a Z P A$ and $p C a Z P A-1,2,3$}

A vector suitable for introducing $l a c Z$ fusion genes in the Drosophila genome was constructed by insertion of the $E$. coli lacZ-coding sequences with the preceding polylinker from pSKS107 (Shapira et al. 1983) into the pCasPeR plasmid (Pirrotta 1988). A 474-nucleotide PstI fragment containing the tra-2 polyadenylation signal was also inserted downstream to the lacZ-coding sequences. This plasmid, called pCaZPA, contains 
unique BamHI and EcoRI restriction sites immediately upstream to the lacZ-coding segment. Fragments containing the promoter and amino-terminal coding region of any gene may be inserted at these sites to make protein fusions with the lacZ gene.

To form pCaZPA-1,2,3, we next inserted the 2.4-kb EcoRISmaI fragment from the tra-2 gene and a small amount of polylinker DNA from the plasmid vector pTZ18R (U.S. Biochemicals) into pCaZPA. This creates an in-frame fusion between the amino-terminal sequences in each of the three major tra-2 ORFs (those encoded by type A, B, and C RNAs) and sequences downstream of the fifth codon in the $l a c Z$ gene. Splicing of RNA from the fusion gene in the type D pattern /which is normally expressed only at very low levels) would form an RNA in which the tra-2 ORF terminates before reaching the lacZ sequences. In addition to tra-2-coding sequences, this plasmid contains $\sim 700$ nucleotides of sequences upstream of the first tra-2 transcription start site. Previous transformation experiments (Goralski et al. 1989) indicate that no additional upstream sequences are needed for normal tra-2 function.

\section{Germ line transformation}

$W^{1118}$ embryos were injected with $300 \mu \mathrm{g} / \mathrm{ml}$ CaZPA-1,2,3 and $100 \mu \mathrm{g} / \mathrm{ml}$ of $\mathrm{p} \Delta 2,3$ (Laski et al. 1986) under standard conditions (Rubin and Spradling 1982; Spradling and Rubin 1982).

\section{$X$-gal staining and immunostaining of larvae and adults}

Adults or larvae were dissected in $0.7 \% \mathrm{NaCl}$ and then fixed and stained with X-gal, as described by Fischer and Maniatis (1988). Immunostaining of whole tissues was performed with anti- $\beta$-galactosidase monoclonal antibody (Promega) and goatanti-mouse FITC-conjugated secondary antibody (Kappel) by use of the procedure described by White and Wilcox (1984).

\section{Acknowledgments}

We thank G. Bohm for excellent assistance in the preparation of media and supplies, $K$. Burtis for advice on DNA sequencing, $T$. Goralski, S. Elledge, and R. Nagoshi for providing phage and plasmid DNAs, M. Kuroda and B. Chase for help with immunostaining, and T. Goralski, M. Kuroda, R. Nagoshi, B. Oliver, and L. Ryner for providing useful comments on this manuscript. W.M. was supported by a postdoctoral fellowship from the Helen Hay Whitney Foundation. M.J.P. was supported by a postdoctoral fellowship from the National Institutes of Health (NIH). Computer resources were funded by the Biomedical Research Technology Program, Division of Research Resources, NIH (grant P41RRR01685). This work was also supported by a U.S. Public Health Service grant.

\section{References}

Adam, S.A., T. Nakagawa, M.S. Swanson, T.K. Woodruff, and G. Dreyfuss. 1986. mRNA polyadenylate-binding protein: Gene isolation and sequencing and identification of a ribonucleoprotein consensus sequence. Mol. Cell. Biol. 6: 2932-2943.

Allan, M., W.G. Lanyon, and J. Paul. 1983. Multiple origins of transcription in the $4.5-\mathrm{kb}$ upstream of the $\epsilon$-globin gene. Cell 35: 187-197.

Amrein, H., M. Gorman, and R. Nothiger. 1988. The sex-determining gene tra-2 of Drosophila encodes a putative RNA binding domain. Cell 55: 1025-1035.

Baker, B.S. 1989. Sex in flies: The splice of life. Nature
340: $521-524$

Baker, B.S. and J.M. Belote. 1983. Sex determination and dosage compensation in Drosophila melanogaster. Annu. Rev. Genet. 17: 345-397.

Baker, B.S. and K. Ridge. 1980. Sex and the single cell: On the action of major loci affecting sex determination in Drosophila melanogaster. Genetics 94: 384-423.

Baker, B.S. and M.F. Wolfner. 1988. A molecular analysis of doublesex, a bifunctional gene that controls both male and female sexual differentiation in Drosophila melanogaster. Genes Dev. 2: 477-489.

Baker, B.S., R.N. Nagoshi, and K.C. Burtis. 1987. Molecular genetic aspects of sex determination in Drosophila. BioEssays 6: $66-70$.

Baker, B.S., K. Burtis, T. Goralski, W. Mattox, and R. Nagoshi. 1989. Molecular genetic aspects of sex determination in Drosophila melanogaster. Genome 31: 638-645.

Baker, C.C., J. Herisse, G. Courtois, F. Gailbert, and E. Ziff. 1979. Messenger RNA for the Ad2 DNA binding protein: DNA sequences encoding the first leader and heterogeneity at the mRNA $5^{\prime}$ end. Cell 18: 569-580.

Barone, M.V., C. Henchcliffe, F.E. Baralle, and G. Paolella. 1989. Cell type specific trans-acting factors are involved in alternative splicing of human fibronectin pre-mRNA. $E M B O$ J. 8: 1079-1085.

Bell, L.R., E.M. Maine, P. Schedl, and T.W. Cline. 1988. Sexlethal a sex determination switch gene, exhibits sex-specific RNA splicing and sequence similarity to RNA binding proteins. Cell 55: 1037-1046.

Belote, J.M. and B.S. Baker. 1982. Sex determination in Drosophila melanogaster: Analysis of transformer-2, a sex transforming locus. Proc. Natl. Acad. Sci. 79: 1568-1572.

. 1983. The dual functions of a sex determination gene in Drosophila melanogaster. Dev. Biol. 95: 512-517.

- 1987. Sexual behavior: Its genetic control during development and adulthood in Drosophila melanogaster. Proc. Natl. Acad. Sci. 84: 8026-8030.

Belote, J.M., A.M. Handler, M.F. Wolfner, K.J. Livak, and B.S. Baker. 1985. Sex-specific regulation of yolk protein gene expression in Drosophila. Cell 40: 339-348.

Belote, J.M., M. McKeown, R.T. Boggs, R. Ohkawa, and B.A. Sosnowski. 1989. Molecular genetics of transformer a genetic switch controlling sexual differentiation in Drosophila. Dev. Genet. 10: 143-154.

Benton, W.D. and R.W. Davis. 1977. Screening $\lambda$ gt recombinant clones by hybridization of single plaques in situ. Science 196: $180-182$.

Bingham, P.M., T.-B. Chou, I. Mims, and Z. Zachar. 1988. On/ off regulation of gene expression at the level of splicing. Trends Genet. 4: 134-138.

Boggs, R.T., P. Gregor, S. Idriss, J.M. Belote, and M. McKeown. 1987. Regulation of sexual differentiation in Drosophila melanogaster via alternative processing of RNA from the transformer gene. Cell 50: 739-747.

Boswell, R.E. and A.P. Mahowald. 1985. tudor, a gene required for assembly of the germ plasm in Drosophila melanogaster. Cell 43: 97-104.

Breathnach, R., C. Benoist, K. O'Hare, F. Gannon, and P. Chambon. 1978. Ovalbumin gene: Evidence for a leader sequence in mRNA and DNA sequences at the exon-intron boundaries. Proc. Natl. Acad. Sci. 75: 4853-4857.

Breitbart, R.E., A. Andreadis, and B. Nadal-Ginard. 1987. Alternative splicing: A ubiquitous mechanism for the generation of multiple protein isoforms from single genes. Annu. Rev. Biochem. 56: 467-495.

Bridges, C.B. 1921. Triploid intersexes in Drosophila melano- 
gaster. Science 54: 252-254.

Burtis, K. and B.S. Baker. 1989. The doublesex gene controls somatic sexual differentiation of Drosophila by producing alternatively spliced mRNAs encoding related sex-specific polypeptides. Cell 56: 997-1010.

Choi, Y.D., P.J. Grabowski, P.A. Sharp, and G. Dreyfuss. 1986. Heterogeneous nuclear ribonucleoproteins: Role in RNA splicing. Science 231: 1534-1539.

Chou, T.-B., Z. Zachar, and P.M. Bingham. 1987. Developmental expression of a regulatory gene is programmed at the level of splicing. EMBO I. 6: 4095-4104.

Cline, T.W. 1978. Two closely linked mutations in Drosophila melanogaster that are lethal in opposite sexes and interact with daughterless. Genetics 90: 683-698.

- 1980. Maternal and zygotic sex-specific gene interactions in Drosophila melanogaster. Genetics 96: 903-926.

1983. The interaction between daughterless and Sexlethal in triploids: A lethal sex-transforming maternal effect linking sex-determination and dosage compensation in Drosophila melanogaster. Dev. Biol. 95: 260-274.

- 1984. Autoregulatory functioning of a Drosophila gene product that establishes and maintains the sexually determined state. Genetics 107: 231-277.

- 1985. Primary events in the determination of sex in Drosophila melanogaster. In Origin and evolution of sex (ed. H.O. Halvorson and A. Monroy), pp. 301-327. Alan R. Liss, New York.

-1986. A female-specific lethal lesion in an X-linked positive regulator of the Drosophila sex determination gene, Sex-lethal. Genetics 113: 641-663.

- 1988. Evidence that sisterless- $a$ and sisterless- $b$ are two of several discrete "numerator elements" of the X/A sex determination signal in Drosophila that switch $S x l$ between two alternative stable expression states. Genetics 119: 829862.

Dreyfuss, G., M.S. Swanson, and S. Pinol-Roma. 1988. Heterogeneous nuclear ribonucleoprotein particles and the pathway of mRNA formation. Trends Biochem. Sci. 13: 8691.

Fischer, J.A. and T. Maniatis. 1988. Drosophila Adh: A promoter element expands the tissue specificity of an enhancer. Cell 53: 451-461.

Flavell, A.J., A. Cowie, S. Legon, and R. Kamen. 1979. Multiple $5^{\prime}$ terminal cap structures in late polyoma virus RNA. Cell 16: $357-371$.

Fujihara, T., M. Kawabe, and K. Oishi. 1978. A sex transforming gene in Drosophila melanogaster. J. Hered. 69: 229-236.

Goralski, T.J., J.-E. Edström, and B.S. Baker. 1989. The sex differentiation locus transformer-2 of Drosophila encodes a polypeptide with similarity to RNA binding proteins. Cell 56: $1011-1018$.

Goldberg, M.L. 1979. Sequence analysis of Drosophila histone genes. Ph.D. thesis, Stanford University, Stanford, California.

Grosschedl, R. and M.L. Birnstiel. 1980. Identification of regulatory sequences in the prelude sequences of an $\mathrm{H} 2 \mathrm{~A}$ histone gene by the study of specific deletion mutants in vivo. Proc. Natl. Acad. Sci. 77: 1432-1436.

Hampson, R.K., L. La Follette, and F.M. Rottman. 1989. Alternative processing of bovine growth hormone mRNA is influenced by downstream exon sequences. Mol. Cell. Biol. 9: 1604-1610.

Henikoff, S. 1984. Unidirectional digestion with exonuclease III creates targeted breakpoints for DNA sequencing. Gene 28: 351-359.

Kozak, M. 1986. Bifunctional messenger RNAs in eukaryotes.
Cell 47: 481-483.

Kramer, A., W. Keller, B. Appel, and R. Luhrman. 1984. The 5' terminus of the RNA moiety of Ul small nuclear ribonucleoprotein particles is required for the splicing of messenger RNA precursors. Cell 38: 299-307.

Laski, F.A. and G.M. Rubin. 1989. Analysis of the cis-acting requirements for germ line-specific splicing of the $P$ element ORF2-ORF3 intron. Genes Dev. 3: 720-728.

Laski, F.A., D.C. Rio, and G.M. Rubin. 1986. Tissue specificity of Drosophila P-element transposition is regulated at the level of mRNA splicing. Cell 44: 7-19.

Maine, E.M., H.K. Salz, P. Schedl, and T.W. Cline. 1985. Sexlethal, a link between sex determination and sexual differentiation in Drosophila melanogaster. Cold Spring Harbor Symp. Quant. Biol. 50: 595-604.

Mardon, H.J., G. Sebastio, and F.E. Baralle. 1987. A role for exon sequences in alternative splicing of the human fibronectin gene. Nucleic Acids Res. 15: 7725-7733.

McKeown, M., J.M. Belote, and R.T. Boggs. 1988. Ectopic expression of the female transformer gene product leads to female differentiation of chromosomally male Drosophila. Cell 53: 887-895.

Merrill, B.M. and K.R. Williams. 1990. Structure/function relationships in hnRNP proteins. In The eukaryotic nucleus: Molecular structure and macromolecular assemblies (ed. P. Strauss and S. Wilson). Telford Press. (in press.)

Merrill, B.M., K.L. Stone, F. Cobianchi, S.H. Wilson, and K.R. Williams. 1988. Phenylalanines that are conserved among several RNA-binding proteins form part of a nucleic acidbinding pocket in the Al heterogeneous nuclear ribonucleoprotein. J. Biol. Chem. 263: 3307-3313.

Mizusawa, S., S. Nishimura, and F. Seela. 1986. Improvement of the dideoxy chain termination method of DNA sequencing by use of deoxy-7-deazaguanosine triphosphate in place of dGTP. Nucleic Acids Res. 14: 1319-1324.

Nagoshi, R.N. and B.S. Baker. 1989. The regulation of sex-specific RNA splicing at the Drosophila doublesex gene: cisacting mutations in exon sequences alter sex-specific RNA splicing patterns. Genes Dev. 4: 89-97.

Nagoshi, R.N., M. McKeown, K.C. Burtis, J.M. Belote, and B.S. Baker. 1988. The control of alternative splicing at genes regulating sexual differentiation in $D$. melanogaster. Cell 53: 229-236.

O'Connell, P. and M. Rosbash. 1984. Sequence, structure and codon preference of the Drosophila ribosomal protein 49 gene. Nucleic Acids Res. 12: 5495-5514.

Oliver, B., N. Perrimon, and A.P. Mahowald. 1988. Genetic evidence that the sans fille locus is involved in Drosophila sex determination. Genetics 120: 159-171.

Oshima, Y. and Y. Gotoh. 1987. Signals for the selection of a splice site in pre-mRNA. Computer analysis of splice site junction sequences and like sequences. $/$. Mol. Biol. 195: 247-259.

Ota, T., A. Fukunaga, M. Kawabe, and K. Oishi. 1981. Interactions between sex transformation mutants of Drosophila melanogaster. I. Hemolymph vitellogenins and gonad morphology. Genetics 99: 429-441.

Padgett, R.A., S.M. Mount, J.A. Steitz, and P.A. Sharp. 1983. Splicing of messenger RNA precursors is inhibited by antisera to small nuclear ribonucleoprotein. Cell 35: 101-107.

Pirrotta, V. 1988. Vectors for P-mediated transformation in Drosophila. In Vectors: A survey of molecular cloning vectors and their uses (ed. R.L. Rodriguez and D.T. Denhardt), pp. 437-456. Butterworths, Boston.

Query, C.C., R.C. Bentley, and J.D. Keene. 1989. A common RNA recognition motif identified within a defined U1 RNA 
binding domain of the 70K U1 snRNP protein. Cell 57: 89101.

Reed, R. and T. Maniatis. 1986. A role for exon sequences and splice-site proximity in splice-site selection. Cell 46: 681690.

Reynolds, G.A., S.K. Basu, T.F. Osborne, D.J. Chin, G. Gil, M.S. Brown, J.L. Goldstein, and K.L. Luskey. 1984. HMG CoA reductase: A negatively regulated gene with unusual promoter and 5' untranslated regions. Cell 38: 275-285.

Rubin, G. and A. Spradling. 1982. Genetic transformation of Drosophila with transposable element vectors. Science 218: 348-353.

Sachs, A.B., M.W. Bond, and R.D. Kornberg. 1986. A single gene from yeast for both nuclear and cytoplasmic polyadenylatebinding proteins: Domain structure and expression. Cell 45: 827-835.

Salz, H.K., E.M. Maine, L.N. Keyes, M.E. Samuels, T.W. Cline, and P. Schedl. 1989. The Drosophila female-specific sex-determination gene, Sex-lethal has stage-, tissue-, and sex-specific RNAs suggesting multiple modes of regulation. Genes Dev. 3: 708-719.

Sanger, F., S. Nicklen, and A.R. Coulson. 1977. DNA sequencing with chain-terminating inhibitors. Proc. Natl. Acad. Sci. 74: 5463-5467.

Schupbach, T. 1982. Autosomal mutations that interfere with sex determination in somatic cell of Drosophila have no direct effect on the germline. Dev. Biol. 89: 117-127.

Shapira, S.K., J. Chou, F.V. Richaud, and M.J. Casabadan. 1983. New versatile plasmid vectors for expression of hybrid proteins coded by a cloned gene fused to $l a c Z$ gene sequences encoding an enzymatically active carboxy-terminal portion of $\beta$-galactosidase. Gene 25: 71-82.

Sillekans, P.T.G., W.J. Habets, R.P. Beijer, and W.J. van Venrooij. 1987. cDNA cloning of the human U1 snRNA-associated A protein: Extensive homology between $\mathrm{U} 1$ and $\mathrm{U} 2$ snRNP-specific proteins. EMBO J. 6: 3841-3848.

Sosnowski, B.A., J.M. Belote, and M. McKeown. 1989. Sex-specific alternative splicing of RNA from the transformer gene results from sequence-dependent splice site blockage. Cell 58: $449-459$.

Spradling, A. and G. Rubin. 1982. Transposition of cloned P elements into Drosophila germ line chromosomes. Science 218: $341-347$.

Steinmann-Zwicky, M. 1988. Sex determination in Drosophila: The X-chromosomal gene $l i z$ is required for $S_{X} l$ activity. $E M B O$ I. 7: 3889-3898.

Streuli, M. and H. Saito. 1987. Regulation of tissue-specific alternative splicing: Exon-specific cis-elements govern the splicing of leukocyte common antigen pre-mRNA. EMBO . 8: $787-796$.

Swanson, M.S., T.Y. Nakagawa, K. LeVan, and G. Dreyfuss. 1987. Primary structure of human nuclear ribonucleoprotein particle $C$ proteins: Conservation of sequence and domain structures in heterogeneous nuclear RNA, mRNA, and pre-rRNA-binding proteins. Mol. Cell. Biol. 7: 1731-1739.

Theissen, H., M. Etzerodt, R. Reuter, C. Schneider, F. Lottspeich, P. Argos, R. Luhrmann, and L. Philipson. 1986. Cloning of the human cDNA for the UI RNA-associated 70K protein. EMBO I. 5: 3209-3217.

Watanabe, T.K. 1975. A new sex-transforming gene on the second chromosome of Drosophila melanogaster. Ipn. I. Genet. 50: 269-271.

White, R.A.H. and M. Wilcox. 1984. Protein products of the bithorax complex in Drosophila. Cell 39: 163-171.

Yang, V.W., M.R. Lerner, J.A. Steitz, and S.J. Flint. 1981. A small nuclear ribonucleoprotein is required for splicing of adenoviral early RNA sequences. Proc. Natl. Acad. Sci. 78: $1371-1375$.

Yanisch-Perron, C., J. Vieira, and J. Messing. 1985. Improved M13 phage cloning vectors and host strains: Nucleotide sequences of the M13mpl9 and pUC19 vectors. Gene 33: $103-119$.

Zachar, Z., T.-B. Chou, and P.M. Bingham. 1987. Evidence that a regulatory gene autoregulates splicing of its transcript. EMBO J. 6: 4105-4111.

Ziff, E.B. and R.M. Evans. 1978. Coincidence of the promoter and capped 5 ' terminus of RNA from the adenovirus 2 major late transcription unit. Cell 15: 1463-1475. 


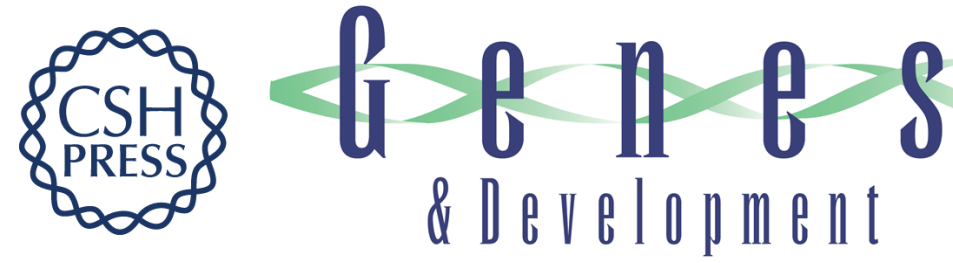

\section{Alternative splicing of the sex determination gene transformer-2 is sex-specific in the germ line but not in the soma.}

W Mattox, M J Palmer and B S Baker

Genes Dev. 1990, 4:

Access the most recent version at doi:10.1101/gad.4.5.789

References This article cites 79 articles, 26 of which can be accessed free at:

http://genesdev.cshlp.org/content/4/5/789.full.html\#ref-list-1

License

Email Alerting

Service

Receive free email alerts when new articles cite this article - sign up in the box at the top right corner of the article or click here.

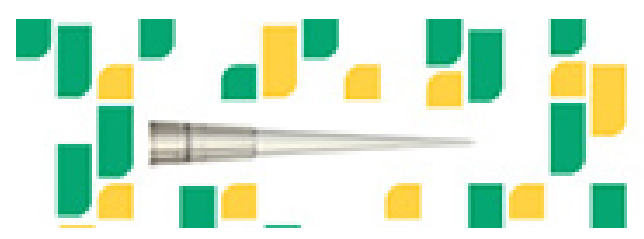

Focused on your science. 